\title{
Exchange Rate Pass-Through on Prices in Macrodata: A Comparative Sensitivity Analysis
}

\author{
Alexander Mihailov* \\ University of Essex
}

November 2005

\begin{abstract}
The paper compares exchange rate pass-through on aggregate prices in the US, Germany and Japan across a number of dimensions. Building on the empirical approaches in the recent literature, our contribution is to perform a thorough sensitivity analysis of alternative pass-through estimates. We find that the econometric method, data frequency and variable proxy employed matter for the precision of details, yet they often agree on some general trends. Thus, pass-through on import prices has declined in the 1990s relative to the 1980s, pass-through on export prices remains country-specific and pass-through on consumer prices is nowadays negligible in all three economies we consider.
\end{abstract}

JEL Classification: F10, F33, F41.

Keywords: exchange rate pass-through, aggregate prices, sensitivity analysis, international comparisons.

*This is a revised version of Chapter 3 of my PhD dissertation at the University of Lausanne (July 2004) and of Discussion Paper No. 568 (October 2003) of the Department of Economics at the University of Essex (with slight variations in the title). I thank Philippe Bacchetta, Christopher Baum, Andreas Fischer, Alessandro Flamini, Hans Genberg, Aude Pommeret and Cédric Tille for comments on earlier drafts. Feedback from the 36th Annual Conference of the Money, Macro and Finance Research Group in London (September 2004), the 6th Annual Conference of the European Trade Study Group in Nottingham (September 2004), the 4th Annual Conference of the European Economic and Finance Society in Coimbra (May 2005), the 22nd Annual Symposium on Banking and Monetary Economics in Strasbourg (June 2005) and seminar participants at Essex (January 2005) is also acknowledged. The usual disclaimer applies. Department of Economics, University of Essex, Wivenhoe Park, Colchester CO4 3SQ, United Kingdom; +44 (0)1206 873351 (phone); +44 (0)1206 872724 (fax); mihailov@essex.ac.uk; http://www.essex.ac.uk/economics/people/staff/mihailov.shtm. 


\section{Contents}

1 Introduction $\quad 4$

2 Data and Estimation Methods $\quad 8$

2.1 Data and Preliminary Tests . . . . . . . . . . . . . . . . 8

2.2 Single-Equation Methods . . . . . . . . . . . . . . . . . . . . . . 9

2.3 VAR System Methods . . . . . . . . . . . . . . . . 12

3 Interpretation of Findings $\quad 17$

3.1 General Findings . . . . . . . . . . . . . . . . . . . . . 17

3.2 Where Our Sensitivity Analysis Matters . . . . . . . . . . . . . 18

3.3 Summary Comparison of Estimates . . . . . . . . . . . . . . . . . 18

3.3.1 Pass-Through on Import Prices . . . . . . . . . . . . . . . . . . . 19

3.3.2 Pass-Through on Export Prices . . . . . . . . . . . . . . 21

3.3.3 Pass-Through on Consumer Prices . . . . . . . . . . . . 22

4 Concluding Comments $\quad 23$

A Data Definitions $\quad 26$

B Test and Estimation Results $\quad 27$

\section{List of Figures}

1 Granger Causality Test Results: Raw Data . . . . . . . . . . . . . . . 36

2 Granger Causality Test Results: Seasonally Adjusted Data . . . . . . . 36

3 United States - Pass-Through on Import Prices from Monthly Data . . 37

$4 \quad$ United States - Pass-Through on Import Prices from Quarterly Data . . 37

5 United States - Pass-Through on Export Prices . . . . . . . . . . . . . . 38

6 United States - Pass-Through on Consumer Prices . . . . . . . . . . . . 38

7 Germany - Pass-Through on Import Prices from Monthly Data . . . . . 39

8 Germany - Pass-Through on Import Prices from Quarterly Data . . . . 39

9 Germany - Pass-Through on Export Prices . . . . . . . . . . . . . . 40

10 Germany - Pass-Through on Consumer Prices . . . . . . . . . . . . . . 40

11 Japan - Pass-Through on Import Prices from Monthly Data . . . . . . . 41

12 Japan - Pass-Through on Import Prices from Quarterly Data . . . . . . 41

13 Japan - Pass-Through on Export Prices . . . . . . . . . . . . . . . . . . 42

14 Japan - Pass-Through on Consumer Prices . . . . . . . . . . . . . . . 42

\section{List of Tables}

1 Single-Equation Estimates of the Pass-Through on Import Prices Obtained Using Import Price Indexes . . . . . . . . . . . . . . . . . . . .

2 Single-Equation Estimates of the Pass-Through on Import Prices Obtained Using Import Unit Values . . . . . . . . . . . . . . . . . . . . 28

3 Pairwise Monthly Correlation Matrix for the Estimated VARs . . . . . .

4 VAR System Estimates of the Pass-Through on Import Prices Obtained Using Import and Export Price Indexes . . . . . . . . . . . . . . . . . .

5 VAR System Estimates of the Pass-Through on Import Prices Obtained Using Import and Export Unit Values . . . . . . . . . . . . . . . 31 
$6 \quad$ VAR System Estimates of the Pass-Through on Export Prices Obtained Using Import and Export Price Indexes . . . . . . . . . . . . . . . 32

7 VAR System Estimates of the Pass-Through on Export Prices Obtained Using Import and Export Unit Values . . . . . . . . . . . . . . . . 33

8 VAR System Estimates of the Pass-Through on Consumer Prices Obtained Using Import and Export Price Indexes . . . . . . . . . . . . 34

9 VAR System Estimates of the Pass-Through on Consumer Prices Obtained Using Import and Export Unit Values . . . . . . . . . . . . 35 


\section{Introduction}

Pass-through from nominal exchange rate changes to import, export, producer and consumer prices is an important issue in international economics, with consequences for the transmission of shocks across countries and for the ensuing macroeconomic policies. It is currently being reconsidered by the profession, both theoretically and empirically, and the present paper forms part of this reconsideration. The direct concern here is not with theory. Our contribution is instead of an empirical nature, insofar we perform a first extensive sensitivity analysis of alternative estimates of exchange rate pass-through from aggregate time series. In doing so, we naturally base our econometric approaches on the main lines of research on the topic. Strangely or not, these seem to be of a polar methodological orientation. One strand in the recent literature relies - at least implicitly if not explicitly - on microfounded economic models to derive or motivate the key specifications to estimate; Campa and L. Goldberg (2005) is among the most up-to-date references, while P. Goldberg and Knetter (1997) is an older but widely cited survey of the field. The other strand is "atheoretical" and simply exploits the correlation structure in the available data; McCarthy (2000) and Coricelli, Jazbec and Masten (2003) have, for instance, applied such statistical methods directly in estimation, while Choudhri, Faruquee and Hakura (2005) have as well used them to help evaluate the predictions of a host of underlying theoretical models. Yet for that same reason of polarity, these two pass-through literatures become also complementary when robustness of estimates is to be checked, as they may well provide extreme points defining the likely empirical range of the phenomenon under study. We here build upon both approaches, addressing some of their weaknesses and comparing their outcomes with our own results.

In theory, the degree of exchange rate pass-through depends on both microeconomic and macroeconomic characteristics. On the microside, pass-through is largely determined by the currencies in which monopolistically competitive firms preset the prices for the differentiated products they sell in globally segmented markets. ${ }^{1}$ In particular, various papers in the new open-economy macroeconomics (NOEM) literature have pointed out in microfounded general equilibrium set-ups that the assumption of local (or consumer's) currency pricing (LCP or CCP $)^{2}$ versus producer's currency pricing (PCP $)^{3}$ is of an essential nature under price rigidity. The reason is that full LCP - by preventing any pass-through from nominal exchange rate changes to import and, ultimately, consumer prices - completely reverses a central result in the Keynesian international macroeconomics tradition known as the expenditure-switching effect: a monetary expansion that depreciates the national currency - and hence, within the short run of price stickiness, the real exchange rate - leads under full LCP to an improvement (not deterioration, as under full PCP) in the inflating country's terms of trade (ToT) and ultimately depresses (and does not stimulate) real economic activity. In reality, however, LCP and PCP will coexist in the prices of exported as well as imported products. ${ }^{4}$ Hence, a first

\footnotetext{
${ }^{1}$ Friberg (1998) argues that the currency of price setting, the currency of invoicing and the currency of payment, although theoretically corresponding to three distinct stages of a typical international trade transaction and hence potentially different, practically coincide "with few known exceptions". Therefore we use "invoicing" and "price setting" interchangeably in the present work (without talking at all about the "currency of payment").

${ }^{2}$ Also termed pricing-to-market (PTM) in a more general sense, following Krugman (1987). Devereux (1997) distinguished LCP as a special case of PTM when prices are fixed in the currency of each destination market.

${ }^{3}$ The standard assumption of open-economy models, both theoretical and empirical, in the MundellFleming-Dornbusch paradigm.

${ }^{4}$ Studies in the early 1970 s on the currency denomination of actual international trade transactions relying on survey data have found that trade in manufacturing goods among developed countries was mainly invoiced in accordance with PCP, implying strong(er) exchange rate pass-through. This regularity has been referred to as "Grassman's law", after the empirical contributions by Grassman (1973 a, b) based on 1968 Swedish trade data. Similar applied work, but using more recent (post Bretton-
} 
determinant of the empirical range of exchange rate pass-through in a given country would be the extent of LCP (or, inversely, PCP) in its trade prices, as shown in a theoretical context by Betts and Devereux $(1996,2000) .{ }^{5}$ A second determinant would then be how much the prices that are preset according to a PCP convention respond to an exchange rate change within certain time horizon, and how much and how fast these responses feed through into other prices along the pricing chain. In a microeconomic sense, this second determinant is related to the issue of how much, and for how long, exporter/importer, distribution and retail firms would be able to squeeze their profit margins in order to maintain the preset prices unchanged (instead of adjusting them, especially upwards) and thus possibly prevent losses of market share, the more so on strategic markets. At a deeper level, such a company's policy would be related to its markup pricing and, ultimately, marginal costs, as discussed in many New Keynesian and NOEM models.

As to the macroeconomic aspects of exchange rate pass-through, these boil down to whether its degree is endogenous to a country's monetary policy and, in a broader sense, macroeconomic performance. Endogenous pass-through works through the endogenous choice of currency of invoicing, as analyzed more explicitly in the theoretical frameworks of Devereux, Engel and Storgaard (2004) and Bacchetta and van Wincoop (2005). Firms would optimally choose to preset prices in a strong(er) currency, and a strong(er) currency is one that does not fluctuate a lot, the latter being itself often a consequence of prudent monetary (and other macro-) policies. Taylor (2000) has, furthermore, pointed out that there is also a reverse effect: low(er) pass-through would, in turn, insulate the domestic economy to a higher extent, so the effectiveness of monetary policy as a stabilization tool would be increased.

Similarly, the empirical exchange rate pass-through literature, that spurred following Krugman (1987), could broadly be divided into microeconomic and macroeconomic studies, depending on the level of aggregation applied to the exchange rate and price data used. Alternatively, it could also be regarded as consisting of two types according to the preferred econometric method. The earlier literature estimated pass-through elasticities in a single-equation context - with empirical specifications often justified by an underlying partial equilibrium model - and almost entirely employing ordinary least squares (OLS) regressions. A major, and somewhat limiting, assumption in this line of research is the exogeneity of regressors. A well-known recent example of this approach is Campa and L. Goldberg (2005). We base on it the first part of our present paper, complementing OLS by instrumental variables (IV) estimation that addresses the mentioned endogeneity problem.

The other type of empirical measures of exchange rate pass-through has generally been skeptical of any economic theory and has therefore become involved with the techniques of vector autoregressions (VARs), mostly simulating and interpreting impulse response functions (IRFs). Contrary to the single-equation method, VARs allow for system estimation where the endogenous variables - usually all in the model, but sometimes with weakly exogenous vectors included as well - are simultaneously determined. Most exchange rate pass-through work within the VAR framework has focused either on orthogonalized (or recursive) IRFs, e.g., McCarthy (2000), or on structural (or restricted) IRFs, e.g., Choudhri, Faruquee and Hakura (2005). The key drawback with orthogonalized IRFs is that they are, although considered "atheoretical", sensitive to the ordering of the variables; while the major problem of IRFs with imposed structural

Woods) data, such as Friberg and Vredin (1997), for example, has however supported an increasing role of pricing-to-market (that is, LCP) practices, implying weak(er) exchange rate pass-through.

${ }^{5}$ Obstfeld and Rogoff (2000) propose a simple correlation test for the dominance of PCP or LCP in real-world economies. Devereux and Engel (2003) and Mihailov (2003 a, b, 2004), among others, have contrasted explicitly in a NOEM setting the effects of these invoicing conventions on welfare and trade under alternative exchange rate regimes. 
restrictions has been argued to be some degree of arbitrariness of such assumptions. The second part of our study complements the standard VAR approaches to exchange rate pass-through embodied in the quoted articles by applying generalized IRFs, due to theoretical work by Koop, Pesaran and Potter (1996) and Pesaran and Shin (1998), where ordering does not matter. Moreover, since elasticities from single-equation regressions and impulse responses from VAR systems are measured differently and cannot be directly compared, this paper proposes a simple "normalization" of the IRF estimates which achieves comparability. It enables us to check whether pass-through estimates obtained from the single-equation literature are largely commensurate with such from the VAR literature.

The theoretical and empirical issues we outlined clearly emphasize the importance of exchange rate pass-through on prices for economic policy. This importance is even greater nowadays, when many central banks target some measure of inflation. More research is therefore needed before a number of remaining problems in understanding and quantifying this pervasive open-economy phenomenon are resolved and become useful for policy makers. In the present paper we address this need for further research by reconsidering the quantitative dimensions of exchange rate pass-through on aggregate prices. More precisely, we are interested here in extracting from macroeconomic time series robust "interval" estimates of pass-through in the three countries whose currencies have been the major international medium of exchange and store of value over the last half of a century, namely the United States (US), Germany and Japan. ${ }^{6}$ Similarly to some of the previous literature, we measure exchange rate pass-through at three stages along the pricing chain, i.e., on import, export and consumer prices. Yet a particular feature of our analysis which distinguishes it from preceding ones is that we purposefully focus on monthly data, this frequency being more relevant than the quarterly one to both exchange rate variability and import/export price rigidity of many individual products in the real world. Apart from comparing our results (i) across the three largest national economies today and (ii) across stages in the pricing chain, we essentially perform an exhaustive sensitivity analysis across four additional dimensions: (iii) frequency, (iv) time, (v) econometric methods and (vi) aggregate import/export price proxies and business cycle controls.

The frequency dimension of the present empirical analysis relates our findings based on monthly data to their analogues obtained from quarterly data. The time dimension consists in splitting up the whole sample in two symmetric subperiods, the 1980s and the 1990s, to look into the dynamic characteristics of the phenomenon. The methodology dimension of our approach progressively complements OLS regressions as in Campa and L. Goldberg (2005) by two-stage least squares (TSLS) estimation, and unrestricted VARs as in McCarthy (2000) and structural VARs as in Choudhri, Faruquee and Hakura (2005) by generalized impulse responses. Moreover, we perform a battery of tests for seasonality, stationarity, cointegration, structural breaks and Granger causality. A final comparison is effected along the proxy dimension, with alternative proxies employed for both trade prices and business cycle indicators: we parallel estimates obtained using the more relevant aggregate import and export price indexes with corresponding ones based on the more readily available approximations of the mentioned indexes which are the unit values of imports and exports; ${ }^{7}$ furthermore, we check how industrial production

\footnotetext{
${ }^{6}$ For instance, in April 1998 the average daily foreign exchange market turnover has been estimated by the Bank for International Settlements (1999) - Statistical Annex, Table E-1 - to be 1260 billions of US dollars in the United States, 430 billions of US dollars in Germany and 300 billions of US dollars in Japan. United Kingdom comes next, with 157 billions of US dollars, followed by Switzerland with 101 billions of US dollars and France with 73 billions of US dollars.

${ }^{7}$ The importance of such a dimension of the study originates in the different methods of calculating these two trade price proxies. Whereas indexes are computed via direct (but not systematic) surveys of exporters and importers concerning the actual prices of international trade transactions, unit values are indirectly obtained from customs declarations registering both volumes and values by transaction.
} 
and employment volume indexes affect the magnitudes of pass-through when replacing real gross domestic product $(G D P)$ as a standard business cycle control variable. ${ }^{8}$ In fact, our different measurement strategies to appropriately quantify pass-through build upon one another in a complementary way, correcting for weaknesses in each one of them if applied in isolation.

All papers we quoted, except one, have relied on quarterly time series, mainly due to lack of monthly import and export price indexes on a wide and comparable international basis. Coricelli, Jazbec and Masten (2003) is the only pass-through paper we are aware of that uses monthly macrodata, but the latter are anyway limited to the 1993-2002 period and to four European Union (EU) candidate economies. Most authors, including McCarthy (2000) and Choudhri, Faruquee and Hakura (2005), have however admitted that monthly data would be more desirable in studying pass-through. We would argue that this is so because time spans of one or two months provide a better approximation than a whole quarter to documented high-frequency volatility of the nominal exchange rate, itself undermining the rigidity of import and export prices in real-world economies. We therefore exploit essentially this line of empirical inquiry, complementing it by a thorough sensitivity analysis. Our approach of focusing on monthly time series and checking across trade price proxies and aggregate demand controls becomes possible, it is true, within a rather narrow set of countries, to ensure highest comparability. ${ }^{9}$ Yet the initial country sample here can subsequently be extended to other economies, in particular when both price indexes and unit values of imports and exports are available for long (and coinciding) time spans, an extremely rare feature in the national macroeconomic accounts at present.

Our results have confirmed that the use of monthly data is quite central when it comes to measuring pass-through dynamics more precisely. This is not surprising, since pass-through has to do with reactions of monopolistically competitive price-setters to (i) exchange rate movements (ii) under sticky prices. On both counts, quarterly observations would miss much of the "action", especially in the short(er) run. We have, in effect, identified an overshooting-type of price adjustment following a change in the exchange rate observed only up to the third month and, hence, invisible in quarterly data. Moreover, we have established that the use of trade price indexes instead of unit values tends to reduce estimates of pass-through by, roughly and on average, 15-20\%; and the use of TSLS instead of OLS by another 10-15\%. Insofar most previous pass-through measures have been extracted from quarterly data and unit values through OLS, we would claim that our study has improved on earlier quantification. Finally, there are two other reasons to expect such an improvement, in terms of both precision and robustness: (i) a monthly sampling provides a three times higher number of observations relative to a quarterly sampling within the same period; and (ii) we have come up with sort of "interval" estimates for the empirical range of pass-through from pooling together magnitudes obtained by a variety of complementary econometric techniques and variable proxies.

The paper is further down organized as follows. The next section first describes the data and some preliminary tests and then discusses the most common approaches to estimating pass-through in related research, motivating our own empirical strategy. Section 3 reports and interprets our estimates across the several dimensions of this comparative study, and the fourth section concludes. Precise definitions and source codes of the data are provided in Appendix A, while Appendix B documents the results from our

Unit values are, therefore, less reliable although more easily available on a broad basis.

${ }^{8}$ It might also be interesting to try some output gap measure in addition to the three aggregate demand proxies enumerated. Yet calculation of output gaps on an internationally comparable basis is rather problematic methodologically and may thus introduce more noise into the estimates.

${ }^{9}$ And at the cost of interpolating GDP series and related deflators in those econometric specifications which include real GDP. 
econometric work. We present and mostly comment throughout our pass-through estimates based on monthly data. The corresponding quarterly based estimates, although summarized in graphs similarly to the monthly based estimates in cumulative quarterly terms, are only mentioned for comparison purposes and to reveal the differences - at times considerable in the precise magnitudes or details but less so in the overall patterns or trends - we detect from the same underlying series across the frequency dimension.

\section{Data and Estimation Methods}

We begin by briefly presenting our data and preliminary tests. We then discuss the econometric methods that have commonly been employed to extract estimates of passthrough from macroeconomic data. In doing so, we are particularly interested to compare single-equation with system estimates of pass-through, i.e., the two most exploited techniques in the literature. Our focus is on the modern versions of these techniques as recently implemented in influential papers, Campa and L. Goldberg (2005) and Choudhri, Faruquee and Hakura (2005), respectively. We broadly base our work on theirs but, more importantly, extend it to address certain weaknesses of estimation and to perform an exhaustive and insightful analysis of robustness.

\subsection{Data and Preliminary Tests}

Our sample consists of International Monetary Fund (IMF) data downloaded from the online version of International Financial Statistics (IFS) accessible via Datastream. ${ }^{10}$ An additional data source, in particular for the employment volume index we use as one alternative to GDP, is Main Economic Indicators (MEI) published by the Organization for Economic Cooperation and Development (OECD) and downloadable via Datastream again. $^{11}$ The definitions of all data we employ and their respective unique IFS or MEI codes are provided in Appendix A.

To obtain higher comparability, we worked on purpose with a sample period divided in two equal halves that is completely identical for all our three economies. ${ }^{12}$ Thus, our whole sample contains 276 monthly observations (1979:07 - 2002:06), with each of the two subsamples, "the 1980s" (1979:07 - 1990:12) and "the 1990s" (1991:01 - 2002:06) covering 138 observations.

The national sources of the data reflected in the original Datastream series are quite heterogeneous, and not all of these variables had been systematically treated for seasonality. To deal with this problem, we relied on explicit seasonality tests by performing the Census X12 procedure. To conclude whether a series displays a seasonal pattern or not, we looked at four formal tests within Census X12. If a time series was found seasonal, the corresponding deseasonalized variable (again produced via Census X12) was further used in our estimation. ${ }^{13}$

To decide on stationarity, we employed three tests that methodologically complement one another, with each of them having been effected in four alternative specifications. Augmented Dickey-Fuller (ADF) unit root tests based on autoregressive models were

\footnotetext{
${ }^{10}$ As nominal GDP and GDP deflators are released in quarterly frequency, they were first interpolated by the spline method.

${ }^{11}$ Since a monthly series was not available for Germany, estimation using the employment volume index for this country was effected only at the quarterly frequency.

${ }^{12}$ To circumvent a discontinuity in the IFS money supply series for Germany, which changed in January 1999 the unit of measurement from deutsche marks (DEM) to euros (EUR), the German M1 aggregate was expressed in marks for the entire sample period. We converted the post-EMU EURdenominated data into DEM-denominated equivalent applying the exchange rate of 1.95583 , which was the same on 31 December 1998 and 1 January 1999.

${ }^{13}$ The seasonality test programs and results are available upon request.
} 
thus performed in parallel with kernel-based Phillips-Perron (PP) unit root tests, with the null for both tests being that of a unit root (i.e., nonstationarity) present. These two tests were supplemented by a test constructed on the opposite null, of stationarity, namely the Kwiatkowski-Phillips-Schmidt-Shin (KPSS) test, and both autoregressive and kernel-based specifications of it were used. ${ }^{14}$ Our conclusion whether a time series is stationary (i.e., integrated of order $0, \mathrm{I}(0)$ ) or not and whether, if nonstationary, it is integrated of order 1 or $2(\mathrm{I}(1)$ or $\mathrm{I}(2))$ was based on the test results. For all time series we work with - and in most cases quite unanimously - our three tests have agreed on the order of integration to be 1 .

\subsection{Single-Equation Methods}

Initial Benchmark: OLS Estimation à la Campa - L. Goldberg (2005) When it comes to single-equation pass-through estimates, the most recent and widely cited study - also summarizing the preceding literature and trying to improve on it - is Campa and L. Goldberg (2005). For this reason, we first applied - as a benchmark their OLS methodology to our sample and two subsamples by country and compared our monthly-based estimates on pass-through on import prices with the respective quarterly ones we also calculated, as well as with the quarterly estimates in the quoted paper. Several specifications, starting from the original one in Campa - L. Goldberg (2005), were used to infer our pass-through measures. For comparability purposes, we report results only from the model which corresponds exactly to that in Campa and L. Goldberg (2005), but adjusted to account for the change from quarterly to monthly data in the lag structure and for the autocorrelation found and corrected for in the residuals. ${ }^{15}$

Tables 1 and 2 in Appendix B document our results for the three countries, two subperiods and two aggregate price proxies from our principal OLS regression, which is the following: ${ }^{16}$

$$
\begin{aligned}
d \ln \left(P M I_{i, t}\right)= & c_{0}+\sum_{k=0}^{12} c_{1, k} d \ln \left(N E E R I n v_{i, t-k}\right)+\sum_{k=0}^{12} c_{2, k} d \ln \left(\text { CGCost }_{i, t-k}\right)+ \\
& +c_{3} d \ln \left(G D P R_{i, t}\right)+\sum_{k=1}^{3} c_{4, k}\left(A R_{i, t-k}\right)+u_{i, t}
\end{aligned}
$$

where $P M I_{i, t}$ is the import price index for country $i$ at time $t ; N E E R \operatorname{Inv}_{i, t}$ is the nominal effective exchange rate (NEER) index defined inversely to the IFS-Datastream original series to correspond to the usual interpretation of depreciation being the increase (not decrease) in the exchange rate, with $k$ in (1) indexing the time lag; CGCost $t_{i, t} \equiv$ $\frac{N E E R_{i, t} C P I_{i, t}}{R E E R_{i, t}}$ is a measure of overall competitiveness Campa and L. Goldberg (2005) suggest as a key control variable, with $C P I_{i, t}$ being the consumer price index (CPI) and $N E E R_{i, t}$ and $R E E R_{i, t}$ being respectively the nominal (NEER) and real (REER)

\footnotetext{
${ }^{14}$ The stationarity test programs and results are available upon request.

${ }^{15}$ More details about all other single-equation specifications we employed in estimating pass-through on import prices à la Campa - L. Goldberg (2005), including regression output and programs, are available upon request.

${ }^{16}$ It broadly corresponds to an implied underlying partial equilibrium model of Bertrand competition where oligopolistic exporters set their prices in a foreign market, e.g., Gross and Schmitt (2000) or Gil-Pareja (2003), but "extended" here to the macrolevel.
} 
effective exchange rate indexes as defined in IFS-Datastream; ${ }^{17} G D P R_{i, t}$ is real GDP; ${ }^{18}$ $A R_{i, t}$ is an autoregressive error term added to correct for identified serial correlation in the residuals, most likely of order 1, 2 or 3 (according to Durbin-Watson tests and Breusch-Godfrey Lagrange multiplier tests we performed); $u_{i, t}$ is the disturbance process.

In order to judge about the effect of employing alternative aggregate import price proxies, in the cases of Germany and Japan (but not for the US, due to lack of data) equation (1) was also estimated with $P M U_{i, t}$, the unit value of imports, replacing $P M I_{i, t}$ above. Furthermore, we applied other business cycle proxies available at a a monthly frequency as controls reflecting aggregate demand conditions: firstly, we replaced $G D P R_{i, t}$ by $I P I_{i, t}$, the industrial production index; secondly, in the cases of the US and Japan (but not for Germany, due to lack of data) equation (1) was re-estimated with $E m p_{i, t}$, an employment volume index from OECD-Datastream, replacing $G D P R_{i, t}$ above. ${ }^{19}$

We also estimated all corresponding quarterly-based specifications (including an additional one with $E m p_{i, t}$ for Germany, since the OECD German employment volume index was available at this particular frequency as well), which differ from (1) in that the respective sums are $\sum_{k=0}^{4}$ for the two lagged explanatory variables and in that there is just one, but quarterly, $A R$ term to correct for first-order serial correlation in the residuals.

Following the literature, we focus on the time profile of pass-through. Pass-through is, consequently, defined by the cumulative sum of the coefficients to the NEERInv $v_{i, t-k}$ variable up to a given lag $k .{ }^{20}$ In tables 1 and 2 in Appendix B we report, and in section 3.3.1 interpret, such pass-through on import prices - in effect, measuring elasticities given the log-difference functional form specified - within the horizon of 1 year.

Parameter Stability and our Sample Split To check for parameter stability, we next performed tests for structural change.

Looking, first of all, at the respective exchange rate data, we identified the most likely - and relevant to pass-through - break points for each of the three countries. Thus, in the case of the inverse US NEER, two potential breakpoint candidates suggested from the data plots stood out. Until March 1985 the US dollar index trended down (appreciation), then - which should partly be related to the Plaza and Louvre accords - until June 1995

\footnotetext{
${ }^{17}$ To capture the shifting relative price of a country's trading partners, Campa and L. Goldberg (2005)

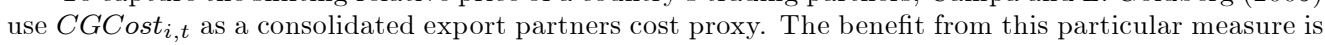
that it is readily constructible from standard macrodata (such as IFS NEERs, REERs and CPIs). For comparability reasons and given the lack of an easy substitute, we also use the Campa - L. Goldberg competitiveness proxy in our computations.

${ }^{18} \mathrm{We}$ allowed as well for lags of real GDP in specification (1). However, this has not significantly affected the pass-through coefficients of interest in the present study, as they are reported in tables 1 and 2 in Appendix B and discussed in section 3.3.1. More detailed results are available upon request.

${ }^{19}$ Thus eliminating the problem of real GDP interpolation; yet introducing other problems, of course. One of them is related to how much the IPI is representative for aggregate economic activity. This point is particularly valid for the three countries in question, given the large services sector in them. Another problem is related to how much employment is responsive to short-run changes in the business cycle.

${ }^{20}$ This approach - implemented in Campa and L. Goldberg (2005) and Choudhri, Faruquee and Hakura (2005), among others - is therefore more interested in the magnitude of the cumulative sum of coefficients rather than in the individual statistical significance of each one of them, which is rarely reported. We can say that, generally, in the case of our OLS and TSLS estimation only two or three exchange rate pass-through coefficients, mostly at monthly lags of 1 and 2, were found to be statistically significant. A similar finding came out of our VAR estimation, yet VARs are notorious on this account anyway. To save space and due to the lack of direct comparability across OLS/TSLS single-equation, on the one hand, and VAR system, on the other, measures of pass-through, as will be discussed further down, we do not present here (analytic or Monte Carlo simulated) cumulative standard errors and corresponding confidence intervals around the point estimates reported in Appendix B. Such tables and graphs are available upon request.
} 
it trended up (depreciation), and finally - perhaps in anticipation of implementing the European Monetary Union (EMU) - the downward trend (appreciation) was restored. We therefore tested our US regression for break points in 1985:03 and 1995:06. The Chow breakpoint test could not reject the null of no structural break for any of these dates as well as for both of them taken together, no matter whether we used the Fstatistic or the log likelihood ratio as test criteria. The Chow forecast test, in turn, produced somewhat less convincing results: it could not reject the null in 1995:06, no matter which of the two alternative test statistics we used; as to the null in 1985:03, it was definitely rejected by the log likelihood ratio (with an associated probability of 0.0000 ) but decisively not rejected by the F-statistic (with an associated probability of 0.9865). For Germany and Japan, the graphs of the inverse NEER indicated a coinciding (local) minimum (strongest currency) in April 1995; but both of the above-mentioned Chow tests could not reject the null of no structural break at that particular point in time. Given the rejection of structural changes at the most critical NEER-related - and, hence, pass-through relevant - points in our data set for Germany and Japan and the only partial and conflicting test results for the US case about a potential break in March 1985, we concluded that the Chow tests did not find any strong evidence for structural breaks in all three economies analyzed.

We then tested for a breakpoint in each of the countries exactly at the split of our sample, i.e., in January 1991. As already said, the reason for a sample split at that particular point in time was to obtain equal (that is, containing the same number of observations) and, hence, more comparable subsample periods. For the US and Germany, both the Chow breakpoint test and the Chow forecast test could not reject the null of no structural change in 1991:01 at all usual levels of significance $(1 \%, 5 \%$ and $10 \%)$. For Japan, however, we obtained somewhat ambiguous results: more precisely, the log likelihood ratio statistic of the Chow breakpoint test rejected the null at $5 \%$ and $10 \%$ but not at $1 \%$, whereas the alternative F-statistic test criterion could not reject the null at these conventional significance levels, yet rejected it at just above $11 \%$; at the same time, the Chow forecast test rejected the null at all usual levels according to the $\log$ likelihood ratio but the F-statistic could not reject the null (with an associated probability as high as 0.9681 ).

Therefore, our sample split in January 1991, from which we report our pass-through measures further down, should not lead to any detrimental consequences with respect to parameter stability. In fact, splitting the sample in two halves is a common strategy in similar empirical work, including in Campa and L. Goldberg (2005). Moreover, given that overall our tests rejected potential breaks at some crucial points evident in the NEER dynamics by country and bearing in mind the inertial nature of the exchange rate pass-through phenomenon, we would take the view that insofar there may be instability of the parameters we estimate over our sample, it would more likely be gradual. In other words, there are no indications to believe that abrupt changes in exchange rate pass-through have occurred at particular distinct points in time throughout our sample period. This conclusion is in line with the previous literature, for instance, Campa and L. Goldberg (2005). For this reason we would interpret exchange rate pass-through as gradually changing over time, which would validate our sample split in two halves and allow a logically-consistent comparison across subsamples of exactly equal size.

Potential Endogeneity and OLS Bias: TSLS Single-equation OLS regressions like the one we began our analysis with are common in empirical research, as they provide at least a first, benchmark estimation. Moreover, OLS is often the estimator with the minimum variance. However, OLS is known to yield estimates which are biased, the more so in small samples, when a regressor is correlated with the error term. In more technical language, OLS leads to inconsistent estimates, on which no economic inference can be 
based. Such endogeneity seems quite likely for some of the right-hand side variables in (1), most notably for the Campa - L. Goldberg cost proxy (by construction). To deal with this problem, we re-estimated the same equation by the usual alternative to OLS, namely two-stage least squares (TSLS), itself a special case of the instrumental variables (IV) method. In our baseline TSLS specification, essentially "mirroring" (1), we employed as instruments $26(=13 \times 2)$ lags of the inverse NEER and the competitiveness proxy and $24(=12 \times 2)$ lags of the dependent variable and the business cycle control. We also experimented with variations of this specification, yet it remained our preferred choice given the limitations of our sample and the interpretability of the econometric output. Our IV/TSLS results are provided in tables 1 and 2 in Appendix B as well, in addition to the OLS estimates. Although the latter were reported for the purpose of direct comparability with their respective analogues in Campa and L. Goldberg (2005), OLS pass-through measures should not be given much credit, because they are very likely to be inconsistent, as noted above. We would thus insist on our TSLS estimates as being more precise: they are, roughly and on average, by $10-15 \%$ lower than the OLS estimates. That is why our TSLS exchange rate pass-through estimates - and not OLS ones - are also present in the comparative graphs in figures $3,4,7,8,11$ and 12 in Appendix B.

To further address the issue of potential endogeneity and to perform a robustness check of our initial pass-through measures across econometric methodology, we moved on to compare our single-equation estimates with those obtained from VAR systems. This involved rescaling, to be described later on, of the impulse responses to an innovation of one standard deviation from the VARs to achieve comparability with the respective elasticities measured from (1).

\subsection{VAR System Methods}

Application of vector autoregressions (VARs) is another widely used method to estimate the dynamic effects of shocks, the more so by theory-agnostic scholars. It quantifies exchange rate pass-through directly from the data in terms of (cumulative) impulse responses to a unit shock in the exchange rate equation of the VAR, not in terms of (cumulative) elasticity, as single-equation methods do. In measuring pass-through from VAR systems, we principally pursued two objectives. First, to base our work on the recent advances in the related literature, essentially building upon them. Second, to stick at the same time to a parsimonious representation, bearing in mind the intended and most efficient use of VAR modelling. We now followed closely another recent and influential study, namely Choudhri, Faruquee and Hakura (2005), but modified their VAR system to a minimal one for our purposes here and complemented their estimation by generalized IRFs.

Testing for Cointegrating Relations Before specifying our VARs, we first duly checked for possible cointegrating relations among the variables to enter our system passthrough estimation. Two problems Choudhri, Faruquee and Hakura (2005) mention (in footnotes) concern unit root and cointegration tests. These authors assume all their series except the interest rate to be I(1) based on Augmented Dickey-Fuller (ADF) tests and Kwiatkowski-Phillips-Schmidt-Shin (KPSS) tests. They also note to have tested for potential cointegration related to 5 theory-suggested interdependencies among their 7 endogenous variables (including purchasing power parity), which has not been found. Coricelli, Jazbec and Masten (2003) go to the other extreme in basing their pass-through estimates on the only recently studied I(2) cointegrated VAR model, claiming that most nominal price data tend to be integrated of order 2 (and identifying 3 cointegrating vectors in the 5 -variable system common to all 4 countries in their sample). 
Taking all these considerations into account, we tried to be explicit and consistent in performing and interpreting our unit root and cointegration tests. We first checked for stationarity of potential cointegrating relations suggested by theory, ${ }^{21}$ such as the (logs of the) terms of trade (ToT), purchasing power parity (PPP), the quantity theory of money $(\mathrm{QTM})^{22}$ and the ratio of the import price index to the CPI. We were not able to reject unit roots in these relations using four different specifications of each of the ADF and the Phillips-Perron (PP) tests.

Moreover, we supplemented this initial check by formal cointegration tests using Johansen's procedure. We generally found quite inconclusive results on the number of cointegrating vectors potentially linking the variables in the 4 theory-induced interdependencies referred to above as well as among the 5 time series we employ in our VARs later, also duly selected given our objective to estimate pass-through on different price indexes and the constraint for a parsimonious representation: import, export and consumer prices, the nominal exchange rate and narrow money (M1). ${ }^{23}$

Having no clear guidance on the number of cointegrating relations, we thus did not engage in attempting to set up reasonable cointegrated VAR models for our data, leaving the avenue in question for further research. This has, moreover, ensured greater comparability between the respective estimates of pass-through obtained via TSLS and via impulse responses from VARs discussed later.

Orthogonalized VAR Impulse Responses The most straightforward way to run a VAR is if the researcher leaves it unrestricted. In fact, the only restriction in this case is the Cholesky ordering which predetermines - by the orthogonalization of shocks - impulse responses and variance decompositions. This is the approach in estimating pass-through preferred, for instance, by McCarthy (2000) and, in essence, Choudhri, Faruquee and Hakura (2005). In applying it to our choice of sample and variables, we first used pairwise Granger-causality tests and priors from economic theory to reduce the possible causal chains to a few most likely subsets of orderings. In a next step, following the advice of Sims (1981), we compared our orthogonalized impulse responses across the four specifications supported by the data, thus providing some sensitivity analysis of our VAR pass-through estimates. These turned out to be rather robust to the four orderings we identified from the Granger tests, which may be partly due to the generally low contemporaneous correlations between the variables in the system. ${ }^{24}$ In addition, generalized VAR impulse responses (to be commented) finally confirmed that substantial errors related to our data-and-theory-informed selection of orderings would be unlikely.

The major benefit from using unrestricted VARs is that they remain (perhaps the only tool) usable when theoretical prescriptions for structural identification of the model are insufficient, if not contradictory or missing at all, as we believe is the case here. That is why we abstain in this paper from experimenting with structural VARs too.

The vector autoregressive (VAR) representation of the simultaneous equations model we apply can be compressed in the following general notation:

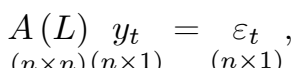

where

\footnotetext{
${ }^{21}$ As done in Choudhri, Faruquee and Hakura (2005).

${ }^{22}$ To be more precise, a simplified version of it implying unitary velocity.

${ }^{23}$ The results from these tests are available upon request.

${ }^{24}$ For the precise numbers, see Table 3 in Appendix B. A look into the table would also indicate a few exceptions in the pairwise correlations which are relatively high.
} 


$$
A(L) \equiv A_{0}-\sum_{k=1}^{\infty} A_{k} L^{k}
$$

is a one-sided matrix polynomial. In (2), the exogenous shocks $\underset{(n \times 1)}{\varepsilon_{t}}$ are written as a distributed lag of current and lagged values of the endogenous variables $\underset{(n \times 1)}{y_{t}}$.

In our particular version of (2) $n=5$, with the five variables making up the endogenous vector $y_{t}$ specified in four orderings (presented below). The lag structure is $(n \times 1)$

approximated by a truncation at $12(k=1,2, \ldots, 12)$ motivated by the monthly frequency of the data.

Under usual stability conditions, e.g., Lütkepohl (2005: chapter 2), Hamilton (1994: chapters 11 and 12) and Watson (1994), the corresponding vector moving average (VMA) representation of the system (2) is:

$$
\underset{(n \times 1)}{y_{t}}=\underset{(n \times n)}{C(L \times 1)} \underset{(n \times 1)}{\varepsilon_{t}}
$$

with

$$
C(L) \equiv \sum_{k=0}^{\infty} C_{k} L^{k}
$$

Like most VAR researchers, we relied on pairwise Granger-causality tests to judge about the most likely ordering of the five variables involved in our unrestricted VAR specifications. The tests were performed for the raw data ${ }^{25}$ as well as for the seasonally adjusted ones, when these latter enter instead the system regressions due to identified seasonality. The outcomes from the Granger tests are summarized in figures 1 (for the raw data) and 2 (with seasonal adjustment) in Appendix B. Looking into these figures, sort of country-specific yet to some extent generalizable, motivated us to concentrate on a (12-lag) VAR alternating the following four orderings of the five variables (in first log-differences with a constant included) for each of the three countries examined.

1. Money $\rightarrow$ exchange rate $\rightarrow$ import prices $\rightarrow$ export prices $\rightarrow$ inflation: ${ }^{26}$ this is the ordering most frequently suggested by the Granger-causality tests (as figures 1 and 2 in Appendix B also show). In our notation:

$$
M 1_{i, t} \rightarrow N E E R I n v_{i, t} \rightarrow P M I_{i, t} \rightarrow P X I_{i, t} \rightarrow C P I_{i, t} .
$$

2. Ordering is the same as in the specification above but with the exchange rate first and money second, as indicated by part of the Granger tests and in accordance with

\footnotetext{
${ }^{25}$ Because seasonal adjusment may have distorted the original relationship between the variables in the system and as a comparability check of the same tests effected with the respective deseasonalized time series.

${ }^{26}$ As our interest is in measuring exchange rate pass-through on aggregate price indexes, we follow Choudhri, Faruquee and Hakura (2005), p. 352, footnote 8, in including only nominal variables in our VARs. These authors claim that adding real output to their basic model has not made much difference to the main results. We were able to confirm that finding in our single-equation estimation, where three real proxies for aggregate demand were alternatively used. It is also worth noting here that our VAR system cannot, in principle, include the same variables as our single equation earlier, because of the polar underlying assumptions, i.e., of exogenous vs endogenous regressors. Furthermore, for reasons of parsimony our VARs were limited to a minimal system of only endogenous variables, as their key purpose was to directly address and overcome (i) the endogeneity problem in OLS as well as (ii) the potential model misspecification in TSLS, as a second single-estimation method we employed.
} 
a wide-spread central bank policy which pays more attention (at least implicitly) to the exchange rate:

$$
N E E R I n v_{i, t} \rightarrow M 1_{i, t} \rightarrow P M I_{i, t} \rightarrow P X I_{i, t} \rightarrow C P I_{i, t} .
$$

3. Essentially, we now impose theoretical priors on the ordering which was most supported by our data, i.e., the one reflected in the first specification. This is done by moving the CPI from last to first in the causal chain, under the logic that inflation is the primary objective of most contemporary central banks, notably including the three countries of our present pass-through study:

$$
C P I_{i, t} \rightarrow M 1_{i, t} \rightarrow N E E R I n v_{i, t} \rightarrow P M I_{i, t} \rightarrow P X I_{i, t} .
$$

4. Ordering is the same as in the preceding specification but with the exchange rate coming before money, in conformity with certain circularity between the Granger causality found for those variables (in particular, for Germany):

$$
C P I_{i, t} \rightarrow N E E R I n v_{i, t} \rightarrow M 1_{i, t} \rightarrow P M I_{i, t} \rightarrow P X I_{i, t} .
$$

As noted earlier, our orthogonalized impulse response estimates of pass-through from the above four specifications have been relatively robust to ordering. This is reflected in the time profile up to the horizon of one year extracted from these impulse responses and summarized by the "interval" estimates (defined by the lowest and the highest point estimates across our VAR orderings) in tables 4 through 9 in Appendix B, which we interpret in section 3. But before doing so, we would now emphasize another novel feature of our empirical strategy aimed at a more robust comparative pass-through measurement. It consists in also employing generalized VARs, the underlying theory for which is introduced next.

Generalized VAR Impulse Responses Building on Koop, Pesaran and Potter (1996), Pesaran and Shin (1998) proposed generalized impulse response analysis as an alternative to the traditional, orthogonalized one. Its main virtue is that it does not require orthogonalization of shocks and is, thus, invariant to the ordering of variables. There is a cost, however, as well: it is that an assumption for the distribution of shocks is anyway needed.

We finally benefited from this recent theoretical contribution to VAR analysis by applying it to our system pass-through estimates, as a complementary check of robustness across methodology. As far as we know, exchange rate pass-through has not yet been estimated using this particular approach. For the sake of clarity, we here briefly summarize generalized VAR impulse response theory. Further details and formal proofs are to be found in the quoted two original sources.

Koop, Pesaran and Potter (1996) define the generalized impulse response function at horizon $l$ of a vector like $y_{t}$ we referred to above as:

$$
G I_{y}\left(l, \delta, \Omega_{t-1}\right)=E\left(y_{t+l} \mid \varepsilon_{t}=\delta, \Omega_{t-1}\right)-E\left(y_{t+l} \mid \Omega_{t-1}\right),
$$

where $\Omega_{t-1}$, a non-decreasing information set, denotes the known history of the economy up to time $t-1$ and $\delta=\left(\delta_{1}, \ldots, \delta_{n}\right)^{\prime}$ is some hypothetical $n \times 1$ vector of shocks hitting the economy at time $t$. Using (4) in (3) gives:

$$
G I_{y}\left(l, \delta, \Omega_{t-1}\right)=C_{l} \delta
$$


which is independent of $\Omega_{t-1}$ but depends on the composition of shocks defined by $\delta .^{27}$ Therefore the choice of a hypothesized vector of shocks, $\delta$, is central to the properties of the impulse response function. The traditional approach, suggested by Sims (1980), is to resolve this problem by surrounding the choice of $\delta$ via the Cholesky decomposition of $\Sigma=E\left(\varepsilon_{t} \varepsilon_{t}^{\prime}\right)$, the variance-covariance matrix of $\varepsilon_{t}$ :

$$
P P^{\prime}=\Sigma \text {, }
$$

where $P$ is an $n \times n$ lower triangular matrix. Then (3) can be rewritten as:

$$
y_{t}=\sum_{k=0}^{\infty}\left(C_{k} P\right)\left(P^{-1} \varepsilon_{t-k}\right)=\sum_{k=0}^{\infty}\left(C_{k} P\right) \xi_{t-k}, \quad t=1,2, \ldots, T,
$$

such that $\xi_{t}=P^{-1} \varepsilon_{t}$ are orthogonalized, namely $E\left(\xi_{t} \xi_{t}^{\prime}\right)=I_{n}$. Hence the $n \times 1$ vector of the orthogonalized impulse response function of a unit shock to the $j$ th equation on $y_{t+l}$ is given by:

$$
\psi_{j}^{o}(l)=C_{l} P e_{j}, \quad l=0,1,2, \ldots,
$$

where $e_{j}$ is an $n \times 1$ selection vector with unity as its $j$ th element and zeros elsewhere.

The alternative approach to that of Sims (1980) proposed by Pesaran and Shin (1998) consists in using (4) directly but, instead of shocking all the elements of the vector $\varepsilon_{t}$, to shock just one, say the $j$ th, of its elements and integrate out the effects of other shocks using an assumed or the historical distribution of the errors. In this case one would have:

$$
G I_{y}\left(l, \delta_{j}, \Omega_{t-1}\right)=E\left(y_{t+l} \mid \varepsilon_{j t}=\delta_{j}, \Omega_{t-1}\right)-E\left(y_{t+l} \mid \Omega_{t-1}\right) .
$$

Assuming further that $\varepsilon_{t}$ has a multivariate normal distribution, Koop, Pesaran and Potter (1996) show that:

$$
E\left(\varepsilon_{t} \mid \varepsilon_{j t}=\delta_{j}\right)=\left(\sigma_{1 j}, \sigma_{2 j}, \ldots, \sigma_{n j}\right)^{\prime} \sigma_{j j}^{-1} \delta_{j}=\Sigma e_{j} \sigma_{j j}^{-1} \delta_{j}
$$

Therefore, the $n \times 1$ vector of the (unscaled) generalized impulse response of the effect of a shock in the $j$ th equation at time $t$ on $y_{t+l}$ is:

$$
\left(\frac{C_{l} \Sigma e_{j}}{\sqrt{\sigma_{j j}}}\right)\left(\frac{\delta_{j}}{\sqrt{\sigma_{j j}}}\right), \quad l=0,1,2 \ldots .
$$

Finally, by setting $\delta_{j}=\sqrt{\sigma_{j j}}$, Pesaran and Shin (1998) derive the scaled generalized impulse response function:

$$
\psi_{j}^{g}(l)=\sigma_{j j}^{-\frac{1}{2}} C_{l} \Sigma e_{j}, \quad l=0,1,2, \ldots .
$$

This latter function measures the effect of one standard error shock to the $j$ th equation at time $t$ on expected values of the vector $y$ at time $t+l$.

The generalized impulse response point estimates of pass-through have, in effect, coincided with those from our second orthogonalized VAR specification among the enumerated above, and are thus included in the range estimates reported in tables 4 through 9 in Appendix B. As shown by Pesaran and Shin (1998), such a coincidence can happen only when impulse responses are estimated for innovations in the first equation in the system, which is the case with our second VAR specification. In all other cases, generalized and orthogonalized time profiles accounting for the system dynamics following a shock are theoretically different, with the generalized impulse response function robust to ordering but the orthogonalized one not. ${ }^{28}$

\footnotetext{
${ }^{27}$ Pesaran and Shin (1998) note that this history invariance property of the impulse response is specific to linear systems and does not carry over to nonlinear ones.

${ }^{28}$ That is why we applied generalized IRF analysis in the first place. Had the data not suggested our
} 


\section{$3 \quad$ Interpretation of Findings}

Having described in sufficient detail our alternative empirical strategies, we now report, compare and interpret our estimates of NEER pass-through on aggregate prices. We start by a few overall conclusions that are valid in general, no matter the particular country, method of estimation, frequency or proxy involved. We then move to a discussion of findings that are specific to one or more of the countries or across methodology, frequency, proxy and time.

\subsection{General Findings}

In the rich set of results obtained from our diverse but complementary estimation techniques, we are able to single out a few conclusions that are robust to all our extensive variations in data and approach. These are as follows.

First, the magnitude and the trend in time of exchange rate pass-through differ substantially at each stage along the pricing chain in all three country cases we examined. No matter the other dimensions of our work, NEER pass-through on import, export and consumer prices is characterized by a quantified measure and by a dominant tendency in the 1980s-1990s which are typical for the particular type of aggregate price index - see the figures in Appendix B. This finding definitely imposes to distinguish and comment pass-through on import, export and consumer prices separately, which we do further down.

Second, a key result that is robust across all modifications of our empirical analysis is that exchange rate pass-through on consumer prices - the weakest in magnitude relative to the other price indexes involved, as expected - is nowadays practically negligible in all three countries. It has declined in Germany (considerably) and Japan (less so) in the 1990s relative to the 1980s, and in the US it had already been at the present low levels - see figures 6, 10 and 14 in Appendix B. This conclusion may have various economic and policy implications. One, of a major relevance for monetary policy, is that nominal exchange rate changes are hardly passed at all onto consumer prices (over a horizon of one year, at least). That finding provides empirical support at the level of consumer prices for the exchange rate disconnect puzzle currently studied in the NOEM literature. It may as well be an indirect indication of a wide-spread importance of local (or consumer) currency practices by monopolistically competitive firms selling in those three national markets, all with a strategic importance. It should also thus explain the failure of purchasing power parity (PPP) in a short-to-medium run. Finally, our result can partly be due to the lower significance of the external sector in those three big countries, at least in relative terms when compared to that in smaller and more open economies.

A third generalizable result is that exchange rate pass-through on import prices has decreased in the 1990s relative to the 1980s: sharply in Germany and Japan and mildly in the US. This finding is robust across frequency and econometric method in the first two economies, yet not in the third country: quarterly data estimates suggest a considerable increase of pass-through on import prices in the US in the 1990s relative to the 1980s, no matter the employed methodology - see figures $3,4,7,8,11,12$. We nevertheless argued, as other researchers we quoted had done, that monthly data should be more reliable in measuring exchange rate pass-through. These conclusions overall support another recent tendency the related literature has been uncovering, namely the fall in the sensitivity of import prices to changes in the nominal exchange rate. This certainly has to do, again, with a stronger role for local currency pricing as well as with pricingto-maket exporter firm strategies consistent with preserving long-term market share at

second ordering, this recent technique could have yielded pass-through estimates deviating away from the empirical range enclosed between the lowest and the highest cumulative orthogonalized responses. 
the cost of temporarily squeezing profits. It also presents evidence for the exchange rate disconnect puzzle, now at the level of import prices.

Fourth, as far as exchange rate pass-through on export prices is concerned, there are no general conclusions to report, unless one: it is country-specific, when trends in the 1990s relative to the 1980s are compared, and it is, moreover, sensitive to the frequency of the data, when measured empirically - see figures 5,9 and 13. For those reasons we are not able to make any other generalization on this particular point.

\subsection{Where Our Sensitivity Analysis Matters}

We would now like to briefly sketch in which dimensions, and how, the extensive sensitivity analysis of exchange rate pass-through we performed in this study really matters for the estimates obtained and the ensuing conclusions.

First, the time dimension of our empirical work has proved important for all three countries we looked at. As we already discussed above, exchange rate pass-through magnitudes have changed with time, considerably on import prices, less so on export prices and consumer prices. This is a finding robust across data frequency and proxy and across econometric method, essentially consistent with similar ones in the literature. It could be interpreted in the sense of a bigger role nowadays, more precisely in the 1990s relative to the $1980 \mathrm{~s}$, for monopolistic competition via strategic pricing-to-market.

Second, the frequency dimension of our sensitivity analysis has mattered to a large extent as well. Monthly vs quarterly sampling of the same underlying data generating process has produced at times quite different conclusions. It has established, for instance, a diverging trend across time for pass-through on import prices in the US and on export prices in Japan. Monthly US data capture a mild decline of pass-through on import prices at all cumulative horizons up to one year in the 1990 s relative to the $1980 \mathrm{~s}$, as we reported, whereas quarterly US data indicate a considerable increase, roughly twice at horizons of one quarter and one year. Monthly Japanese data witness, in turn, no big change in pass-through on export prices, while quarterly ones measure a dramatic decline in the 1990s relative to the 1980s. Moreover, estimates from German quarterly data - although not resulting in diverging overall conclusions - slightly understate the magnitude of exchange rate pass-through on import prices when compared with the respective monthly data ones at all time horizons up to one year and no matter the econometric method and the variable proxy used. All those findings show the importance of measuring exchange rate pass-through at a monthly vs quarterly frequency. The very nature of the pass-through phenomenon requires the use of higher-frequency data, as most researchers in the field would agree.

Third, the variable proxy dimension and, similarly, the estimation methodology dimension - but the latter as judged only for exchange rate pass-through on import prices, whose measurement was alternatively effected and compared by single-equation (OLS and TSLS) vs system methods (orthogonalized and generalized impulse responses from VARs) - have mattered too for the details of precision, but not that much for the overall trends and patterns recovered from the data. More comments on those two key dimensions of our study follow immediately.

\subsection{Summary Comparison of Estimates}

Because of the considerable differences uncovered across the three stages in the pricing chain, we conclude the discussion of our results with a summary of the most interesting facts along each of them compared across countries. 


\subsubsection{Pass-Through on Import Prices}

Single-Equation Methodology Comparing first our TSLS findings on the empirical range of pass-through from the exchange rate to import prices in tables 1 and 2 in Appendix $\mathrm{B}$, we are able to reveal the following main conclusions across several dimensions of our study.

Across Proxy There is some difference in the time profile extracted, using TSLS estimation, from the two aggregate import price proxies, indexes and unit values - mostly at horizons of 2-3 months, hence 1 quarter; yet this difference likewise tends to diminish over longer horizons, 1 year in particular. Thus, for the cumulative pass-through on import prices, both our proxies result in quite close estimates, notably over the whole sample (108.9\% using import price indexes and $118.4 \%$ using unit values of imports for Germany; and $87.0 \%$ and $94.3 \%$, respectively, for Japan) and during the 1990s subperiod ( $88.1 \%$ and $114.5 \%$ for Germany; $42.6 \%$ and $55.1 \%$ for Japan). To sum-up, the use of import unit values in place of price indexes seems to matter in terms of the precise magnitudes of NEER pass-through, especially in the short run of 1, 2 and 3 months (hence, 1 quarter), but not that much in capturing the general time profile.

As for business cycle controls in the Campa - L. Goldberg (2005) regression, using industrial production indexes or employment volume indexes instead of real GDP does not considerably affect our results either. ${ }^{29}$ The interpolation of GDP-related data we used in our monthly pass-through measurement does not thus appear to be crucial.

Across Country An interesting, but more or less known, result from the crosscountry comparison of our single-equation estimates of exchange rate pass-through on import prices is the very low pass-through - along all studied horizons - in the US relative to Germany and Japan. Only $\frac{1}{4}$ of a NEER change is estimated to be passed on to import prices over one year in the US and only about $2 \%$ in the first month, during the whole sample period as well as (a little bit more) in the 1990s subsample. By contrast, our estimates for Germany and Japan present evidence for a virtually full pass-through on import prices over the same horizon of one year within the total sample, with more than half of the cumulative change occurring in the first month after the shock.

How Do Our Results Compare to Those in Campa - L. Goldberg (2005)? Our NEER pass-through elasticities on import price indexes obtained along the Campa - L. Goldberg (2005) methodology but via TSLS from monthly data and a corresponding specification, equation (1), differ considerably from theirs, estimated from the same specification but via OLS from quarterly data and unit values. ${ }^{30}$ This mismatch is partly due to noncoinciding (i) sample, (ii) frequency, (iii) proxy and (iv) method. Yet we would expect our TSLS estimates to be more precise, having improved on account of frequency and proxy, but mostly because they overcome the endogeneity problem and the related OLS bias discussed earlier. For comparison, at one quarter Campa and L. Goldberg (2005) obtain ${ }^{31} 23 \%$ for the US, $55 \%$ for Germany and $43 \%$ for Japan, within their whole sample of 1975-1999; at a horizon of one year the respective pass-through on import prices they find is $42 \%, 80 \%$ and $113 \%$. Our corresponding TSLS estimates for $1979-2002$ are $14.4 \%$ and $24.2 \%$ for the US, $81.3 \%$ and $108.9 \%$ for Germany and $65.8 \%$ and $87.0 \%$ for Japan, using price indexes (as noted, employing unit values changes our

\footnotetext{
${ }^{29}$ More details are available upon request.

${ }^{30}$ Due to a lesser similarity of our single-equation specification and sample with the one summarized in P. Goldberg and Knetter (1997), we would not engage here in comparing our quantitative findings with theirs.

${ }^{31}$ See their Table 1.
} 
numbers but not so much the trends). We thus measure import price NEER passthrough twice lower in the US relative to Campa and L. Goldberg (2005), by one-third to one-fourth higher in Germany, with full pass-through at one year, and higher in Japan at one quarter but lower at one year, i.e., a much flatter time pattern with almost full pass-through at one year horizon. ${ }^{32}$

VAR System Methodology The single-equation methods of estimating cumulative exchange rate pass-through on import prices at some horizon $l$ we applied measure, more precisely, the elasticity of a given import price (or unit value) index, $P M I_{t l}$ (or $P M U_{t l}$ ), with respect to the nominal exchange rate, $N E E R I n v_{t l}$, that is, the partial derivative:

$$
\frac{\partial\left(d \ln P M I_{t l}\right)}{\partial\left(d \ln N E E R I n v_{t l}\right)}, \quad l>0 .
$$

The VAR system methods of estimating cumulative exchange rate pass-through on import prices at the same horizon $l$ we also employed measure, in turn, the impulse response of a given import price (or unit value) index, $P M I_{t l}$ (or $P M U_{t l}$ ), with respect to an innovation of one standard deviation ${ }^{33}$ in the NEER equation of the VAR, $\varepsilon_{t l}^{N E E R I n v}$, that is, the partial derivative:

$$
\frac{\partial\left(d \ln P M I_{t l}\right)}{\partial \varepsilon_{t l}^{N E E R I n v}}, \quad l>0 .
$$

It is obvious from the two formulas above that a direct comparison of the passthrough estimates across methodology is irrelevant. To be able to compare our measures of pass-through in (7) and (8) we applied a simple but informative transformation to the impulse response values at all time horizons. It consists in rescaling, or "normalizing", the impulse responses to an innovation in the exchange rate VAR equation in the following way:

$$
\frac{\frac{\partial\left(d \ln P M I_{t l}\right)}{\partial \varepsilon_{t l}^{N E E R I n v}}}{\frac{\partial\left(d \ln N E E R I n v_{t l}\right)}{\partial \varepsilon_{t l}^{N E E R I n v}},} \quad l>0 .
$$

\footnotetext{
${ }^{32}$ It may be somewhat astonishing, at first sight, to arrive at estimates of exchange-rate pass-through exceeding $100 \%$. Yet there are at least two potential, and complementary, explanations for such a finding, present not only in our study but also in related work by others. The first one is of an econometric nature: the result may simply be an artefact of model misspecification. Moreover, it may as well be the outcome of accumulating many insignificant coefficients at the longer horizons of measurement. However, there is a deeper, economic reason not to quickly discard pass-through estimates on import prices, in particular, higher than the magnitude of their cause, the nominal exchange rate change. Our argument here is that the elasticity of the import price index with respect to the exchange rate may in some cases be higher than one. This is likely in a domestic market where there are no close substitutes to the imported product, so if the seller/exporter enjoys a monopolistic position and faces inelastic demand, the import price may be changed more than the underlying change in the exchange rate to extract additional profits. And even if import prices are, conversely, inelastic with respect to the exchange rate, elastic responses over given horizons should not be excluded during the adjustment dynamics. These are intriguing special cases that may be worth addressing in future theoretical work.

${ }^{33}$ Lütkepohl (2005, chapter 2, p. 53) notes that the average size of the innovations occurring in a system depends on their standard deviation. For that reason, impulse response analysis is more useful when innovations of one standard deviation are considered rather than unit shocks, as we do in our VARs. Moreover, such concerns prove valid in our particular case here of comparing pass-through in three economies where the variability of the NEER, and hence of the exchange rate shock processes, has differed considerably across country. To see this, the respective standard deviation of the log-difference of the NEER for our sample has been 1.9 percentage points (pp) in the US; 0.7 pp (more than twice lower) in Germany; and $2.6 \mathrm{pp}$ in Japan (i.e., nearly 4 times higher than in Germany).
} 
As can now be seen clearly, applying formula (9) translates the pass-through impulse response to one standard deviation shock in the exchange rate equation into a passthrough elasticity measured in percentage changes. In effect, our rescaled VAR passthrough estimates reported in tables 4-9 express what part (in \%) is passed on to various price proxies at different horizons $l$ following a unit change in the NEER in period $t$. With the help of this transformation, we can judge to what extent the econometric method applied (single-equation TSLS vs simultaneous VAR system, in particular) may affect our principal findings. To our knowledge, this direct comparison of single-equation measures of exchange rate pass-through with VAR system ones constitutes another novelty of the present study.

We next summarize our conclusions when comparing the estimates of NEER passthrough on import prices obtained using VARs, with the impulse responses appropriately rescaled as documented in tables 4 and 5 , with those obtained via TSLS in tables 1 and 2 .

Across Frequency An interesting observation which comes out from our monthly pass-through estimates - but impossible to be captured at a quarterly frequency - is related to the short-run dynamics of price adjustment to exchange rate changes. It is rather common across stages in the pricing chain, variable proxies, time periods and country cases. There is a "spike", generally in the first or second month, in our passthrough estimates, usually followed by a "dive" in the next month. Such a pattern obviously exhibits certain "overshooting", which appears typical for all three economies we focused on.

Across Proxy Except for Germany in the 1990s, the use of one or the other of our two proxies for the aggregate prices of imports in the VARs did not appear to change too much, as it was with our TSLS estimates. More precisely, unit value inferred impulse response measures now tend to slightly understate pass-through on import prices in the shorter run (up to one quarter). Sometimes this understatement is complemented by a weak overstatement in the longer run (one year).

Across Country For the US, the single-equation point estimate à la Campa - L. Goldberg (2005) is most of the time inside the system range estimate summarizing the four alternative orderings of our VARs; for Germany and Japan, it is often not very far from that range. If there are differences to distinguish between TSLS and VAR passthrough estimates on import prices, these would concern the cumulative response at the longer horizons (3 quarters and 1 year) and, mostly, the 1990s subperiod (when VARobtained values are somewhat higher). Otherwise and en gros, our TSLS and VAR measures of pass-through on import prices are largely commensurate. This is rather insightful, insofar neither the underlying econometric methods and assumptions, nor the included variables in the specifications are the same. Our result thus points to a substantial degree of robustness on that account, at least concerning the general trends and patterns recovered from the data.

\subsubsection{Pass-Through on Export Prices}

Looking at the pass-through from exchange rate changes to export prices in tables 6 and 7 in Appendix B, we could summarize our findings in the following manner.

Across Proxy Although again preserving some very general trends, the estimates resulting from unit values now produce time profiles that are more dissimilar with respect to the corresponding estimates obtained from price indexes. Moreover, in the 
Japanese case unit value estimates are indicative of a falling pass-through on the prices of exports in the 1990s relative to the $1980 \mathrm{~s}$, while price index-based measures reverse this conclusion. In the case of Germany estimates based on indexes present evidence for a pass-through that diminishes considerably in the 1990s relative to the 1980s, especially over the one-year horizon, whereas estimates from unit values indicate only a modest reduction. Our proxy check, therefore, flashes a red light: measurement problems involved in unit values and price indexes may impair, as here, the robustness of inferred pass-through trends.

Across Country The empirical range of exchange rate pass-through across countries is, again, quite varied when pass-through on export prices is analyzed. The lowest pass-through is in the US (like it was with pass-through on import prices), of the order of $13.7-15.4 \%$ at the one-year horizon for the whole sample period.

\subsubsection{Pass-Through on Consumer Prices}

We finally compare our estimates of pass-through on consumer prices, reported in tables 8 and 9 in Appendix B. Several conclusions that hold in common for the three countries considered seem to have shaped out.

Across Frequency As far as NEER pass-through on consumer price levels is concerned, frequency largely does not matter. A general finding is that at this final stage in the pricing chain, relevant for consumer decision-making and, hence, for any microfounded macroeconomic outcomes, pass-through is low to negligible.

Across Proxy The proxy employed in our IRF estimates of pass-through on consumer prices does not matter either. For the whole sample and the 1990s (but much less so for the 1980s) empirical ranges along all respective horizons are close in value, thus producing a similar time profile in Germany and in Japan.

Across Country A major conclusion is thus that there is nowadays a practically nil pass-through from exchange rate movements to consumer prices in all three countries examined.

How Do Our Results Compare to Those in Choudhri, Faruquee and Hakura (2005)? Using orthogonalized impulse responses from a somewhat different sample period (1979:1-2001:3) and VAR specification with seven endogenous and two exogenous variables over quarterly data, Choudhri, Faruquee and Hakura (2005) measure the exchange rate pass-through at various stages in the pricing chain for the six non-US G-7 countries. Are our monthly VAR findings at the relevant horizons close to theirs? ${ }^{34}$ Generally yes, concerning consumer prices for both Japan and Germany and at both horizons of principal interest, one quarter and one year; yet our pass-through measures on import and export prices differ, often considerably in magnitude. The latter three authors report ${ }^{35}$ pass-through on import prices (in fact, estimated from unit values of imports and exports) of $80 \%$ at one quarter and $134 \%$ at one year for Japan and $39 \%$ and $77 \%$, respectively, for Germany; our corresponding VAR interval estimates (employing price indexes) are $66.4-66.5 \%$ and $88.4-89.2 \%$ for Japan and $83.3-86.8 \%$ and 128.4-136.3\% for Germany. Pass-through on export prices is, correspondingly, $50 \%$ and $50 \%$ for Japan and $3 \%$ and $16 \%$ for Germany in Choudhri et al. against our estimates

\footnotetext{
${ }^{34}$ Due to a lesser similarity of our VAR specification and sample with those in McCarthy (2000), we would not compare here our pass-through ranges with his related results.

${ }^{35}$ In their Table 1, p. 354
} 
of $60.3-60.4 \%$ and $44.2-44.4 \%$ for Japan and $18.7-19.4 \%$ and $33.3-40.3 \%$ for Germany. Finally, pass-through from exchange rate changes to consumer prices is measured by the three coauthors at $-1 \%$ and $4 \%$ for Japan and $15 \%$ and $20 \%$ for Germany while our estimates are, respectively, $0.5-0.7 \%$ and $3.8-3.9 \%$ for Japan $4.7-7.9 \%$ and $9.1-13.6 \%$ for Germany.

\section{Concluding Comments}

The present paper built on a few well-known recent empirical studies of exchange rate pass-through using macrodata to measure, compare and interpret the likely range of this phenomenon in three leading national economies in the world: the US, Germany and Japan. We employed various methods and specifications and obtained results which contain a number of interesting aspects to analyze. Focusing on monthly data to comply with a sampling that is more relevant to exchange rate variability, itself one of the determinants of import/export price stickiness, we inferred pass-though estimates that are broadly similar - when expressed in quarterly terms - to those extracted in earlier related papers, notably from OLS regressions in Campa - L. Goldberg (2005) and from VAR systems in Choudhri, Faruquee and Hakura (2005), only with respect to consumer prices. As for the pass-through on import and export prices, our estimates are not very close to the respective ones in the two cited articles, and we have suggested why our measures may be better. In summing-up, the following novel features of our work, as well as some key differences along its several dimensions, are worth emphasizing.

An overall conclusion is that the empirical range of exchange rate pass-through on prices varies across (i) economies, (ii) data frequencies, (iii) periods of time, (iv) methods of estimation, (v) aggregate price measures, (vi) stages along the pricing chain and (vii) horizons of analysis. Any generalization thus needs to be careful. Yet abstracting from the specificity of some aspects of pass-through we commented in detail above, we would like to stress at least four important and rather robust results from our comparative study, with implications for the transmission of shocks (monetary or real) reflected in exchange rate changes on various prices and, hence, for macroeconomic policies. First, in the three countries we examined, pass-through on import prices has declined in the 1990s relative to the 1980s; but pass-through on export prices remains very country-specific; as for consumer prices, exchange rate pass-through seems to be nowadays practically negligible over all horizons of up to one year. Second, the econometric method and the measurement proxy used matter for the precise magnitudes and time patterns, yet they often - although not always - accord on the general trends. Third, the US - when compared to Germany and Japan, at least - proves to be quite a particular economy, with import price level that is rather insensitive to US dollar fluctuations. Fourth, as far as our focus on the frequency dimension of pass-through estimates is concerned, a general insight from performing the same calculations with monthly as well as with (corresponding) quarterly data is that when passing from the higher to the lower frequency a lot of short-term dynamics is lost. This is mostly due to an averaging effect inherent in the quarterly data which "washes out" an intense overshooting-type dynamics of price adjustment following a NEER change captured by the monthly data in the very short run of less than one quarter. In a similar sense, the present empirical work also revealed evidence for a difference in the magnitudes, and sometimes in the trends, of pass-through estimated from different data frequency. 


\section{References}

[1] Bank for International Settlements (BIS), Triennial Central Bank Survey of Foreign Exchange and Derivatives Market Activity 1998 (Basel, 1999).

[2] Bacchetta, Philippe and Eric van Wincoop, "A Theory of Currency of Denomination in International Trade", Journal of International Economics, forthcoming.

[3] Betts, Caroline M. and Michael B. Devereux, "The Exchange Rate in a Model of Pricing to Market", European Economic Review 40 (1996), 1007-1021.

[4] Betts, Caroline M. and Michael B. Devereux, "Exchange Rate Dynamics in a Model of Pricing to Market", European Economic Review 50 (2000), 215-244.

[5] Campa, Jose M. and Linda Goldberg, "Exchange Rate Pass-Through into Import Prices", Review of Economics and Statistics 87:4 (2005), forthcoming.

[6] Choudhri, Ehsan, Hamid Faruquee and Dalia Hakura, "Explaining the Exchange Rate Pass-Through in Different Prices", Journal of International Economics 65:2 (2005), 349-374.

[7] Coricelli, Fabrizio, Bostjan Jazbec and Igor Masten, "Exchange Rate Pass-Through in Candidate Countries", Centre for Economic Policy Research Discussion Paper No. 3894 (2003).

[8] Devereux, Michael B., "Real Exchange Rate and Macroeconomics: Evidence and Theory", Canadian Journal of Economics 30 (1997), 773-808.

[9] Devereux, Michael B. and Charles Engel, "Monetary Policy in the Open Economy Revisited: Price Setting and Exchange-Rate Flexibility", Review of Economic Studies 70:4 (2003), 765-783.

[10] Devereux, Michael B., Charles Engel and Peter E. Storgaard, "Endogenous Exchange Rate Pass-Through When Nominal Prices Are Set in Advance", Journal of International Economics 63:2 (2004), 263-291.

[11] Friberg, Richard, "In Which Currency Should Exporters Set Their Prices?", Journal of International Economics 45 (1998), 59-76.

[12] Friberg, Richard and Anders Vredin, "Exchange Rate Uncertainty and the Microeconomic Benefits of EMU", Swedish Economic Policy Review 4 (1997), 547-594.

[13] Gil-Pareja, Salvador, "Pricing to Market Behaviour in European Car Markets", European Economic Review 47 (2003), 945-962.

[14] Goldberg, Pinelopi K. and Michael Knetter, "Goods Prices and Exchange Rates: What Have We Learned?", Journal of Economic Literature 35 (1997), 1243-1272.

[15] Grassman, Sven, "A Fundamental Symmetry in International Payment Patterns", Journal of International Economics 3 (1973 a), 105-116.

[16] Grassman, Sven, Exchange Reserves and the Financial Structure of Foreign Trade (Farnborough: Saxon House, 1973 b).

[17] Gross, Dominique and Nicolas Schmitt, "Exchange Rate Pass-Through and Dynamic Monopoly: An Empirical Investigation", Journal of International Economics $52: 1$ (2003), 83-112. 
[18] Hamilton, James, Time Series Analysis (Princeton, New Jersey: Princeton University Press, 1994).

[19] Koop, Gary, M. Hashem Pesaran and Simon M. Potter, "Impulse Response Analysis in Nonlinear Multivariate Models", Journal of Econometrics 74 (1996), 119-147.

[20] Krugman, Paul, "Pricing to Market When the Exchange Rate Changes", in Sven W. Arndt and J. David Richardson (Eds.), Real-Financial Linkages among Open Economies (Cambridge, Massachusetts: MIT Press, 1996).

[21] Lane, Philip, "The New Open Economy Macroeconomics: A Survey", Journal of International Economics 54 (2001), 235-266.

[22] Lütkepohl, Helmut, New Introduction to Multiple Time Series Analysis (Springer: 2005).

[23] McCarthy, Jonathan, "Pass-Through of Exchange Rates and Import Prices to Domestic Inflation in Some Industrialized Countries", Federal Reserve Bank of New York, Staff Report 111 (2000).

[24] Mihailov, Alexander, "Effects of the Exchange-Rate Regime on Trade under Monetary Uncertainty: The Role of Price Setting", Discussion Paper No. 566, Department of Economics, University of Essex (2003 a).

[25] Mihailov, Alexander, "When and How Much Does a Peg Increase Trade? The Role of Trade Costs and Import Demand Elasticity under Monetary Uncertainty", Discussion Paper No. 567, Department of Economics, University of Essex (2003 b).

[26] Mihailov, Alexander, The Exchange-Rate Regime and Trade: A New OpenEconomy Macroeconomics Perspective with Pass-Through Empirics, PhD Dissertation, Ecole des HEC, University of Lausanne (2004).

[27] Pesaran, M. Hashem and Yongcheol Shin, "Generalized Impulse Response Analysis in Linear Multivariate Models", Economics Letters 58 (1998), 17-29.

[28] Obstfeld, Maurice and Kenneth Rogoff, "New Directions for Stochastic Open Economy Models", Journal of International Economics 50 (2000), 117-153.

[29] Sarno, Lucio, "Towards a New Paradigm in Open Economy Modeling: Where Do We Stand?", Federal Reserve Bank of St. Louis Review 83 (2000), 21-36.

[30] Sims, Christopher, "Macroeconomics and Reality", Econometrica 48 (1980), 1-48.

[31] Sims, Christopher, "An Autoregressive Index Model for the US, 1948-1975" in Jan Kmenta and James B. Ramsey (Eds.), Large-Scale Macro-Econometric Models (Amsterdam: North Holland, 1981, 283-327).

[32] Taylor, John B., "Low Inflation, Pass-Through and the Pricing Power of Firms", European Economic Review 44:7 (2000), 1389-1408.

[33] Watson, Mark, "Vector Autoregressions and Cointegration", in Robert F. Engle, and Daniel L. McFadden (Eds.), Handbook of Econometrics IV (1994), Elsevier Science. 


\section{A Data Definitions}

\section{Country Codes}

- US: United States

- BD: Germany

- JP: Japan

\section{Data Sources}

- IFS: International Financial Statistics, International Monetary Fund (IMF), via Datastream

- MEI: Main Economic Indicators, Organization for Economic Cooperation and Development (OECD), via Datastream

\section{Variable Codes and Sources}

- PMI: import price index, IFS (USI76.X.F, BDI76.X.F, JPI76.X.F)

- PMU: unit value of imports, IFS (BDI75...F, JPI75...F)

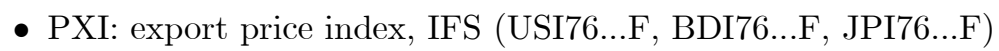

- PXU: unit value of exports, IFS (BDI74...F, JPI74...F)

- NEER: nominal effective exchange rate index, IFS (USI..NEUE, BDI..NEUE, JPI..NEUE)

- REER: real effective exchange rate index, IFS (USI..REUE, BDI..REUE, JPI..REUE)

- NEERInv: inverse of the nominal effective exchange rate index $\equiv \frac{1}{\text { NEER }}$

- CPI: consumer price index, IFS (USI64...F, BDI64...F, JPI64...F)

- Nominal GDP (quarterly), IFS (USI99B.CB, BDI99B.CB, JPI99B.CB)

- GDP deflator (quarterly), IFS (USI99BIRH, BDI99BIRH, JPI99BIRH)

- Real GDP: nominal GDP divided by the GDP deflator $\equiv \frac{\text { nominal GDP }}{\text { GDP deflator }}$

- IPI: industrial production index, IFS (USI66..IG, BDI66..IG, JPI66..IG)

- Employment (monthly, for the US and Japan): employment volume index, MEI (USOEM040G, JPOEM040G)

- Employment (quarterly, for Germany): employment volume index, MEI (BDOEM040H)

- C-G Cost: Campa - L. Goldberg (2005) cost competitiveness proxy $\equiv \frac{\text { NEER } \times \text { CPI }}{\text { REER }}$

- M1 (for the US and Japan): narrow money M1, IFS (USI34...A, JPI34...A)

- CC (for Germany): currency in circulation, IFS (BDL34A.NA)

- DD (for Germany): demand deposits, IFS (BDL34B.NA)

- M1 (for Germany): narrow money $\equiv \mathrm{CC}+\mathrm{DD}$

\section{Notation for Transformed Data}

- SA: seasonally adjusted (via the Census X12 procedure) series used in estimation, after finding evidence for seasonality

- dl: first difference in natural logarithms of a series (i.e., percentage change) 


\section{B Test and Estimation Results}

\begin{tabular}{|c|c|c|c|c|c|}
\hline \multicolumn{6}{|c|}{ Pass-Through on the Import Price Index Following NEER Depreciation, } \\
\hline & OLS; TSLS & OLS; & TSLS & OLS; & TSLS \\
\hline \multicolumn{6}{|c|}{ PANEL I: Whole Sample Period (July 1979 - June 2002, 276 observations) } \\
\hline & United States & \multicolumn{2}{|c|}{ Germany } & \multicolumn{2}{|r|}{ Japan } \\
\hline month 1 , contemporaneous & $3.6 ;$ & 58.6 ; & 51.4 & $57.9 ;$ & 58.8 \\
\hline month 2 , cumulative & $12.7 ; \quad 10.7$ & 77.7 ; & 71.4 & 66.1; & 66.7 \\
\hline quarter 1 , cumulative & 18.3 & 86.8; & 81.3 & 67.8 ; & 65.8 \\
\hline end-quarter 2, cumulative & 19.9 & 97.9; & 94.4 & 86.9; & 80.9 \\
\hline end-quarter 3 , cumulative & 25.5; & 109.8; & 109.8 & 93.4; & 84.3 \\
\hline year 1 , cumulative & 24.4 & 109.0; & 108.9 & 100.0; & 87.0 \\
\hline \multicolumn{6}{|c|}{ 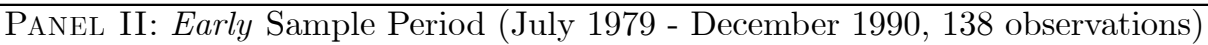 } \\
\hline & United States & \multicolumn{2}{|c|}{ Germany } & \multicolumn{2}{|r|}{ Japan } \\
\hline month 1, contemporaneous & 2.5 & 71.9 ; & 70.8 & 64.0 & 65.1 \\
\hline month 2 , cumulative & 12.0 & 88.6; & 91.3 & 81.2 & 82.5 \\
\hline quarter 1 , cumulative & 21.0 & 103.7; & 109.4 & 88.6 ; & 86.9 \\
\hline end-quarter 2, & 31.6 & 115.7 & 127.9 & 112.3; & 107.4 \\
\hline end-quarter 3, & 39.6 & 127.3; & 140.3 & 113.3; & 113.4 \\
\hline end-year 1 , cumulative & 33.3 & 130.0; & 137.2 & 121.9; & 116.1 \\
\hline \multicolumn{6}{|c|}{ PANEL III: Late Sample Period (January 1991 - June 2002, 138 observations) } \\
\hline & United States & \multicolumn{2}{|c|}{ Germany } & \multicolumn{2}{|r|}{ Japan } \\
\hline month 1 , contemporaneous & 4.9 & 44.4 & 38.3 & 49.3; & 40.2 \\
\hline month 2 , cumulative & 16.2 & 63.6 ; & 57.1 & 49.5; & 40.1 \\
\hline quarter 1 , & 14.6 & 64.4 ; & 57.4 & 44.3; & 33.5 \\
\hline end-quarter 2 , & 12.9 & 72.3 ; & 61.1 & 55.5 ; & 44.1 \\
\hline end-quarter 3 & 15.4; & 93.6; & 81.7 & 55.2 & 43.7 \\
\hline end-year 1 , cumulative & 27.4 & 100.9; & 88.1 & 52.8 & 42.6 \\
\hline
\end{tabular}

Table 1: Single-Equation Estimates of the Pass-Through on Import Prices Obtained Using Import Price Indexes 


\begin{tabular}{|c|c|c|c|}
\hline \multicolumn{4}{|c|}{ Pass-Through on the Unit Value of Imports Following NEER Depreciation, $\%$} \\
\hline & OLS; $\quad$ TSLS & OLS; & SSLS \\
\hline \multicolumn{4}{|c|}{ 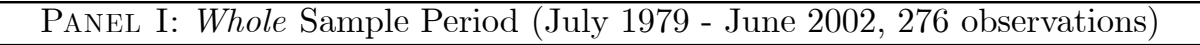 } \\
\hline & Germany & \multicolumn{2}{|r|}{ Japan } \\
\hline month 1 , contemporaneous & $41.2 ; \quad 31.1$ & 47.6; & 52.7 \\
\hline month 2, cumulative & $84.7 ; \quad 81.8$ & 85.5; & 89.5 \\
\hline quarter 1 , cumulative & $80.6 ; \quad 77.0$ & 76.2 ; & 79.8 \\
\hline end-quarter 2, cumulative & $116.6 ; \quad 117.9$ & 92.4; & 90.7 \\
\hline end-quarter 3, cumulative & $121.8 ; \quad 126.8$ & 97.2 ; & 92.5 \\
\hline year 1 , cumulative & $110.3 ; \quad 118.4$ & 104.0; & 94.3 \\
\hline \multicolumn{4}{|c|}{ PANEL II: Early Sample Period (July 1979 - December 1990, 138 observations) } \\
\hline & Germany & \multicolumn{2}{|r|}{ Japan } \\
\hline month 1 , contemporaneous & $74.8 ; \quad 83.9$ & 57.5 & $\overline{58.4}$ \\
\hline month 2 , cumulative & $94.2 ; \quad 103.9$ & 105.2 & 106.8 \\
\hline quarter 1 , cumulative & $109.2 ; \quad 122.9$ & 96.1; & 95.8 \\
\hline end-quarter 2, cumulative & $131.1 ; \quad 156.0$ & 123.6 & 119.3 \\
\hline end-quarter 3, cumulative & $165.1 ; \quad 190.3$ & 112.0; & 110.1 \\
\hline end-year 1, cumulative & $155.4 ; \quad 177.0$ & 125.1 & 118.4 \\
\hline \multicolumn{4}{|c|}{ PANEL III: Late Sample Period (January 1991 - June 2002, 138 observations) } \\
\hline & Germany & \multicolumn{2}{|r|}{ Japan } \\
\hline month 1, contemporaneous & $5.8 ; \quad(-0.7)$ & 37.8 & 35.1 \\
\hline month 2 , cumulative & $62.7 ; \quad 59.1$ & 68.0 ; & 66.1 \\
\hline quarter 1 , cumulative & $43.6 ; \quad 37.4$ & $54.3 ;$ & 51.6 \\
\hline end-quarter 2 , cumulative & $86.2 ; \quad 80.3$ & 58.7 ; & 56.2 \\
\hline end-quarter 3 , cumulative & $95.0 ; \quad 96.1$ & 60.3 & 57.8 \\
\hline end-year 1 , cumulative & 107.2; & 57.3; & 55.1 \\
\hline
\end{tabular}

Table 2: Single-Equation Estimates of the Pass-Through on Import Prices Obtained Using Import Unit Values 


\begin{tabular}{|c|c|c|c|c|}
\hline \multicolumn{5}{|c|}{$\begin{array}{c}\text { Whole Sample Period (July } 1979 \text { - June 2002, } 276 \text { observations) } \\
\end{array}$} \\
\hline \multicolumn{5}{|l|}{$\overline{\mathrm{US}}$} \\
\hline & dlM1(SA) & dlNEERInv & dIPMI & dlPXI(SA) \\
\hline dlNEERInv & 0.12 & & & \\
\hline dlPMI & 0.02 & 0.12 & & \\
\hline $\operatorname{dlPXI}(\mathrm{SA})$ & 0.13 & -0.07 & 0.24 & \\
\hline dlCPI(SA) & -0.01 & -0.03 & 0.50 & 0.26 \\
\hline \multicolumn{5}{|l|}{ Germany } \\
\hline & dlM1(SA) & dlNEERInv(SA) & dlPMI(SA) & dlPXI(SA) \\
\hline dlNEERInv(SA) & 0.11 & & & \\
\hline dlPMI(SA) & -0.09 & 0.57 & & \\
\hline $\operatorname{dlPXI}(\mathrm{SA})$ & -0.14 & 0.46 & 0.78 & \\
\hline dlCPI(SA) & -0.08 & 0.02 & 0.37 & 0.28 \\
\hline \multicolumn{5}{|l|}{ Japan } \\
\hline & dlM1(SA) & dlNEERInv & dlPMI(SA) & dIPXI \\
\hline dlNEERInv & 0.04 & & & \\
\hline dlPMI(SA) & 0.01 & 0.68 & & \\
\hline dlPXI & 0.05 & 0.93 & 0.68 & \\
\hline dlCPI(SA) & -0.13 & -0.02 & 0.13 & 0.02 \\
\hline
\end{tabular}

Table 3: Pairwise Monthly Correlation Matrix for the Estimated VARs 


\begin{tabular}{|c|c|c|c|}
\hline \multicolumn{4}{|c|}{$\begin{array}{l}\text { Pass-Through on the Import Price Index Following NEER Depreciation, } \% \\
\end{array}$} \\
\hline \multirow{2}{*}{\multicolumn{4}{|c|}{ min - max range of 4 OIRF estimates (includes GIRF one) }} \\
\hline PANEL I: Whole Sar & & & \\
\hline & United States & Germany & Japan \\
\hline month 1 , contemporaneous & $2.6-3.6$ & $57.3-60.1$ & $57.7-57.8$ \\
\hline month 2 , cumulative & $10.3-11.7$ & $74.4-77.0$ & $63.3-63.3$ \\
\hline quarter 1 , cumulative & $16.3-18.3$ & $83.3-86.8$ & $66.4-66.5$ \\
\hline end-quarter 2, cumulative & $15.4-18.4$ & $108.3-112.9$ & $78.4-78.9$ \\
\hline end-quarter 3 , cumulative & $19.2-22.1$ & $118.5-126.2$ & $84.1-84.5$ \\
\hline year 1 , cumulative & $17.1-20.5$ & $128.4-136.3$ & $88.4-89.2$ \\
\hline \multicolumn{4}{|c|}{ PANEL II: Early Sample Period (July 1979 - December 1990, 138 observations) } \\
\hline & United States & Germany & Japan \\
\hline month 1 , contemporaneous & $1.3-2.7$ & $67.6-73.8$ & $56.4-56.7$ \\
\hline month 2 , cumulative & $10.3-12.3$ & $85.7-91.2$ & $66.3-67.3$ \\
\hline quarter 1 , cumulative & $17.3-20.3$ & $101.5-107.4$ & $76.0-78.0$ \\
\hline end-quarter 2, cumulative & $22.0-25.9$ & $125.0-134.01$ & $94.8-96.3$ \\
\hline end-quarter 3, cumulative & $26.3-30.9$ & $134.8-145.7$ & $106.1-108.5$ \\
\hline end-year 1 , cumulative & $15.4-22.5$ & $150.3-160.1$ & $120.9-122.1$ \\
\hline \multicolumn{4}{|c|}{ 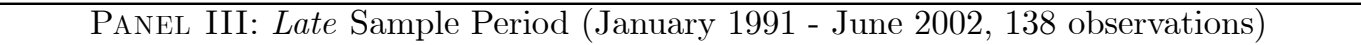 } \\
\hline & United States & Germany & Japan \\
\hline month 1 , contemporaneous & $5.4-7.0$ & $36.4-39.2$ & $53.4-53.8$ \\
\hline month 2 , cumulative & $15.8-16.7$ & $44.1-50.0$ & $47.6-48.1$ \\
\hline quarter 1 , cumulative & $16.4-17.8$ & $40.7-46.8$ & $37.5-38.6$ \\
\hline end-quarter 2, cumulative & $18.0-23.4$ & $38.3-50.3$ & $30.7-31.8$ \\
\hline end-quarter 3 , cumulative & $28.3-31.9$ & $50.2-65.0$ & $31.9-34.0$ \\
\hline end-year 1 , cumulative & $35.3-37.9$ & $47.8-64.3$ & $32.7-35.0$ \\
\hline
\end{tabular}

Table 4: VAR System Estimates of the Pass-Through on Import Prices Obtained Using Import and Export Price Indexes 


\begin{tabular}{|c|c|c|}
\hline \multicolumn{3}{|c|}{ Pass-Through on the Unit Value of Imports Following NEER Depreciation, \% } \\
\hline \multicolumn{3}{|c|}{ min - max range of 4 OIRF estimates (includes GIRF one) } \\
\hline \multirow{2}{*}{\multicolumn{3}{|c|}{$\begin{array}{cc}\text { PANEL I: Whole Sample Period (July } 1979-\text { June } 2002,276 \text { observations) } & \\
\text { Germany } & \text { Japan }\end{array}$}} \\
\hline & & \\
\hline month 1 , contemporaneous & $37.3-37.6$ & $45.4-45.7$ \\
\hline month 2 , cumulative & $72.1-73.3$ & $72.6-73.0$ \\
\hline quarter 1 , cumulative & $78.1-80.3$ & $78.6-78.7$ \\
\hline end-quarter 2 , cumulative & $112.7-115.7$ & $84.7-85.0$ \\
\hline end-quarter 3 , cumulative & $113.6-118.9$ & $85.1-86.1$ \\
\hline year 1 , cumulative & $116.9-126.5$ & $86.0-87.3$ \\
\hline \multicolumn{3}{|c|}{ PANEL II: Early Sample Period (July 1979 - December 1990, 138 observations) } \\
\hline & Germany & Japan \\
\hline month 1 , contemporaneous & $62.5-67.2$ & $52.2-54.7$ \\
\hline month 2 , cumulative & $81.8-88.5$ & $91.0-94.2$ \\
\hline quarter 1 , cumulative & $100.3-110.4$ & $105.5-112.5$ \\
\hline end-quarter 2 , cumulative & $125.8-136.3$ & $109.2-114.8$ \\
\hline end-quarter 3 , cumulative & $137.5-156.8$ & $116.4-119.6$ \\
\hline end-year 1, cumulative & $152.6-168.8$ & $128.3-132.0$ \\
\hline \multicolumn{3}{|c|}{ PANEL III: Late Sample Period (January 1991 - June 2002, 138 observations) } \\
\hline & Germany & Japan \\
\hline month 1 , contemporaneous & $(-0.7)-8.0$ & $33.8-34.2$ \\
\hline month 2 , cumulative & $65.1-66.0$ & $54.8-54.8$ \\
\hline quarter 1 , cumulative & $36.4-42.0$ & $48.8-49.8$ \\
\hline end-quarter 2 , cumulative & $94.3-99.3$ & $38.8-39.7$ \\
\hline end-quarter 3 , cumulative & $90.1-99.6$ & $36.6-37.6$ \\
\hline end-year 1, cumulative & $108.9-114.7$ & $37.6-39.0$ \\
\hline
\end{tabular}

Table 5: VAR System Estimates of the Pass-Through on Import Prices Obtained Using Import and Export Unit Values 


\begin{tabular}{|c|c|c|c|}
\hline \multicolumn{4}{|c|}{$\begin{array}{l}\text { Pass-Through on the Export Price Index Following NEER Depreciation, } \% \\
\end{array}$} \\
\hline \multirow{2}{*}{\multicolumn{4}{|c|}{ min - max range of 4 OIRF estimates (includes GIRF one) }} \\
\hline & & & \\
\hline & United States & Germany & Japan \\
\hline month 1 , contemporaneous & $(-2.6)-(-2.9)$ & $13.2-14.6$ & $59.4-59.5$ \\
\hline month 2 , cumulative & $(-1.2)-(-0.8)$ & $16.1-17.7$ & $60.2-60.4$ \\
\hline quarter 1 , cumulative & $2.6-3.0$ & $18.7-19.4$ & $60.3-60.4$ \\
\hline end-quarter 2, cumulative & $4.6-5.0$ & $24.9-27.3$ & $52.4-52.5$ \\
\hline end-quarter 3 , cumulative & $12.9-13.4$ & $28.8-33.3$ & $45.1-45.2$ \\
\hline year 1 , cumulative & $10.8-11.4$ & $33.3-40.3$ & $44.2-44.4$ \\
\hline \multicolumn{4}{|c|}{ 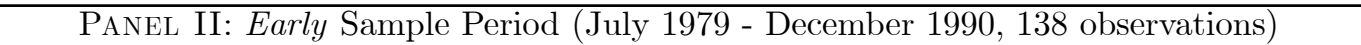 } \\
\hline & United States & Germany & Japan \\
\hline month 1 , contemporaneous & $(-7.7)-(-6.2)$ & $12.8-14.0$ & $54.7-55.3$ \\
\hline month 2 , cumulative & $(-5.9)-(-4.2)$ & $15.8-16.9$ & $57.0-57.7$ \\
\hline quarter 1 , cumulative & $(-2.5)-(-1.6)$ & $14.9-19.9$ & $57.2-57.8$ \\
\hline end-quarter 2, cumulative & $(-2.1)-0.0$ & $26.3-28.7$ & $47.9-48.2$ \\
\hline end-quarter 3 , cumulative & $7.4-8.6$ & $31.8-35.7$ & $40.0-40.5$ \\
\hline end-year 1 , cumulative & $8.0-10.3$ & $38.5-43.8$ & $39.3-39.8$ \\
\hline \multicolumn{4}{|c|}{ 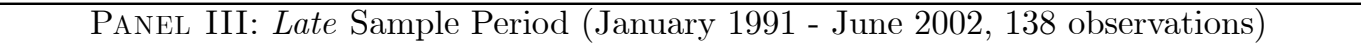 } \\
\hline & United States & Germany & Japan \\
\hline month 1 , contemporaneous & $2.4-3.0$ & $12.5-13.2$ & $59.3-59.9$ \\
\hline month 2 , cumulative & $4.4-4.8$ & $15.3-16.8$ & $58.0-58.1$ \\
\hline quarter 1 , cumulative & $8.1-8.3$ & $14.1-16.2$ & $57.0-57.4$ \\
\hline end-quarter 2, cumulative & $17.5-19.2$ & $10.4-16.2$ & $49.2-49.3$ \\
\hline end-quarter 3 , cumulative & $19.3-21.5$ & $10.4-16.6$ & $46.8-47.3$ \\
\hline end-year 1 , cumulative & $18.3-20.1$ & $12.6-19.5$ & $41.4-41.7$ \\
\hline
\end{tabular}

Table 6: VAR System Estimates of the Pass-Through on Export Prices Obtained Using Import and Export Price Indexes 


\begin{tabular}{lcr}
\hline \hline \multicolumn{3}{c}{ Pass-Through on the Unit Value of Exports Following NEER Depreciation, \% } \\
\hline \multicolumn{3}{c}{ min - max range of 4 OIRF estimates (includes GIRF one) } \\
\hline \multicolumn{2}{c}{ PANEL I: Whole Sample Period (July 1979 - June 2002, 276 observations) } \\
\hline month 1, contemporaneous & Germany & Japan \\
month 2, cumulative & $11.6-12.9$ & $25.6-25.7$ \\
quarter 1, cumulative & $19.4-20.5$ & $56.1-56.3$ \\
end-quarter 2, cumulative & $24.9-27.2$ & $60.8-61.0$ \\
end-quarter 3, cumulative & $31.9-35.6$ & $45.8-46.2$ \\
year 1, cumulative & $41.5-44.9$ & $37.3-37.6$ \\
\hline \multicolumn{2}{c}{ PANEL II: Early Sample Period (July } & $1979-$ December 1990, 138 observations) \\
\hline & Germany & Japan \\
\hline month 1, contemporaneous & $5.0-6.9$ & $32.2-33.5$ \\
month 2, cumulative & $15.5-16.3$ & $61.9-63.3$ \\
quarter 1, cumulative & $14.8-20.5$ & $66.2-68.8$ \\
end-quarter 2, cumulative & $27.0-35.8$ & $51.7-52.5$ \\
end-quarter 3, cumulative & $33.8-47.9$ & $48.2-49.9$ \\
end-year 1, cumulative & $42.4-54.5$ & $43.3-46.0$ \\
\hline \multicolumn{2}{c}{ PANEL III: Late Sample Period (January $1991-$ June 2002, 138 observations) } \\
\hline \multicolumn{2}{c}{ Japan } \\
\hline month 1, contemporaneous & Germany & $16.7-17.1$ \\
month 2, cumulative & $7.5-12.0$ & $49.1-49.7$ \\
quarter 1, cumulative & $18.1-22.4$ & $54.1-54.7$ \\
end-quarter 2, cumulative & $29.2-32.6$ & $36.2-37.1$ \\
end-quarter 3, cumulative & $34.2-44.6$ & $31.8-32.5$ \\
end-year 1, cumulative & $50.1-56.0$ & $28.2-28.8$ \\
\hline
\end{tabular}

Table 7: VAR System Estimates of the Pass-Through on Export Prices Obtained Using Import and Export Unit Values 


\begin{tabular}{|c|c|c|c|}
\hline \multicolumn{4}{|c|}{ Pass-Through on the Consumer Price Index Following NEER Depreciation, $\%$} \\
\hline & min - max range & of 4 OIRF estimat & ludes GIRF one) \\
\hline \multicolumn{4}{|c|}{ PANEL I: Whole Sample Period (July 1979 - June 2002, 276 observations) } \\
\hline & United States & Germany & Japan \\
\hline month 1 , contemporaneous & $0.0-0.6$ & $0.0-3.4$ & $0.0-0.1$ \\
\hline month $2, \mathrm{c}$ & $(-0.3)-0.4$ & $2.8-6.5$ & $(-0.5)-(-0.4)$ \\
\hline quarter $1, \mathrm{c}$ & $(-1.4)-(-0.6)$ & $4.7-7.9$ & $0.5-0.7$ \\
\hline end-quarter 2 & $(-2.9)-(-1.8)$ & $5.5-10.3$ & $1.4-1.5$ \\
\hline end-quarter & $(-1.8)-(-0.3)$ & $7.0-12.2$ & $3.5-3.7$ \\
\hline year 1 , cumulative & $(-1.4)-0.2$ & $9.1-13.6$ & $3.8-3.9$ \\
\hline \multicolumn{4}{|c|}{ 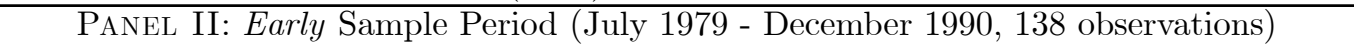 } \\
\hline & United States & Germany & Japan \\
\hline month $1, \mathrm{c}$ & $0.0-0.7$ & $0.0-4.1$ & $(-0.4)-0.0$ \\
\hline month 2 , cumulative & $(-0.8)-0.1$ & $4.0-8.1$ & $(-1.2)-(-0.8)$ \\
\hline quarter 1 , cumulative & $(-2.7)-(-1.7)$ & $7.6-11.5$ & $1.3-1.7$ \\
\hline lative & $(-4.3)-(-2.8)$ & $15.3-20.7$ & $3.2-3.6$ \\
\hline quarte & $(-1.1)-0.7$ & $15.7-21.2$ & $5.4-6.0$ \\
\hline end-year 1 , cumulative & $(-2.3)-(-0.1)$ & $21.6-28.0$ & $5.7-6.2$ \\
\hline \multicolumn{4}{|c|}{ PANEL III: Late Sample Period (January 1991 - June 2002, 138 observations) } \\
\hline & United States & Germany & Japan \\
\hline month $1, \mathrm{c}$ & $0.0-1.1$ & $0.0-4.4$ & $0.0-1.1$ \\
\hline month 2 , cumulative & $0.1-1.0$ & $(-0.9)-3.1$ & $(-1.1)-(-0.3)$ \\
\hline quarter 1 , & $(-0.9)-0.1$ & $(-3.0)-1.0$ & $(-1.3)-(-0.4)$ \\
\hline end-quarter 2 , cumulative & $-4.8)-(-1.9)$ & $-19.2)-(-8.5)$ & $(-0.8)-0.0$ \\
\hline end-quarte & $(-1.7)-(-0.2)$ & $(-14.8)-(-6.5)$ & $(-0.7)-0.1$ \\
\hline end-year 1 , cumulative & $0.1-1.5$ & $(-12.9)-(-4.8)$ & $(-0.3)-0.5$ \\
\hline
\end{tabular}

Table 8: VAR System Estimates of the Pass-Through on Consumer Prices Obtained Using Import and Export Price Indexes 


\begin{tabular}{|c|c|c|}
\hline \multirow{3}{*}{\multicolumn{3}{|c|}{$\begin{array}{l}\text { Pass-Through on the Consumer Price Index Following NEER Depreciation, } \% \\
\text { min - max range of } 4 \text { OIRF estimates (includes GIRF one) } \\
\text { PANEL I: Whole Sample Period (July } 1979 \text { - June 2002, } 276 \text { observations) }\end{array}$}} \\
\hline & & \\
\hline & & \\
\hline & Germany & Japan \\
\hline month 1 , contemporaneous & $0.0-2.4$ & $0.0-0.4$ \\
\hline month 2 , cumulative & $3.8-6.7$ & $(-0.6)-(-0.3)$ \\
\hline quarter 1 , cumulative & $6.0-8.5$ & $0.5-0.8$ \\
\hline end-quarter 2 , cumulative & $6.8-9.9$ & $1.4-1.8$ \\
\hline end-quarter 3 , cumulative & $7.8-10.3$ & $3.5-4.0$ \\
\hline year 1 , cumulative & $8.6-11.7$ & $4.0-4.4$ \\
\hline \multicolumn{3}{|c|}{ PANEL II: Early Sample Period (July 1979 - December 1990, 138 observations) } \\
\hline & Germany & Japan \\
\hline month 1 , contemporaneous & $0.0-3.8$ & $0.0-1.7$ \\
\hline month 2 , cumulative & $2.8-7.1$ & $(-1.5)-(-0.2)$ \\
\hline quarter 1 , cumulative & $8.4-12.0$ & $3.2-4.3$ \\
\hline end-quarter 2, cumulative & $15.3-21.3$ & $4.0-5.2$ \\
\hline end-quarter 3 , cumulative & $15.1-21.4$ & $5.8-7.3$ \\
\hline end-year 1 , cumulative & $20.2-28.1$ & $7.5-9.1$ \\
\hline \multicolumn{3}{|c|}{ PANEL III: Late Sample Period (January 1991 - June 2002, 138 observations) } \\
\hline & Germany & Japan \\
\hline month 1 , contemporaneous & $0.0-9.3$ & $0.0-0.8$ \\
\hline month 2 , cumulative & $(-0.9)-8.3$ & $(-1.4)-(-0.8)$ \\
\hline quarter 1 , cumulative & $(-2.9)-6.4$ & $(-1.5)-(-0.8)$ \\
\hline end-quarter 2, cumulative & $(-11.5)-1.1$ & $(-1.3)-(-0.5)$ \\
\hline end-quarter 3 , cumulative & $(-10.0)-1.3$ & $(-0.8)-0.0$ \\
\hline end-year 1 , cumulative & $(-9.5)-2.1$ & $(-0.5)-0.4$ \\
\hline
\end{tabular}

Table 9: VAR System Estimates of the Pass-Through on Consumer Prices Obtained Using Import and Export Unit Values 


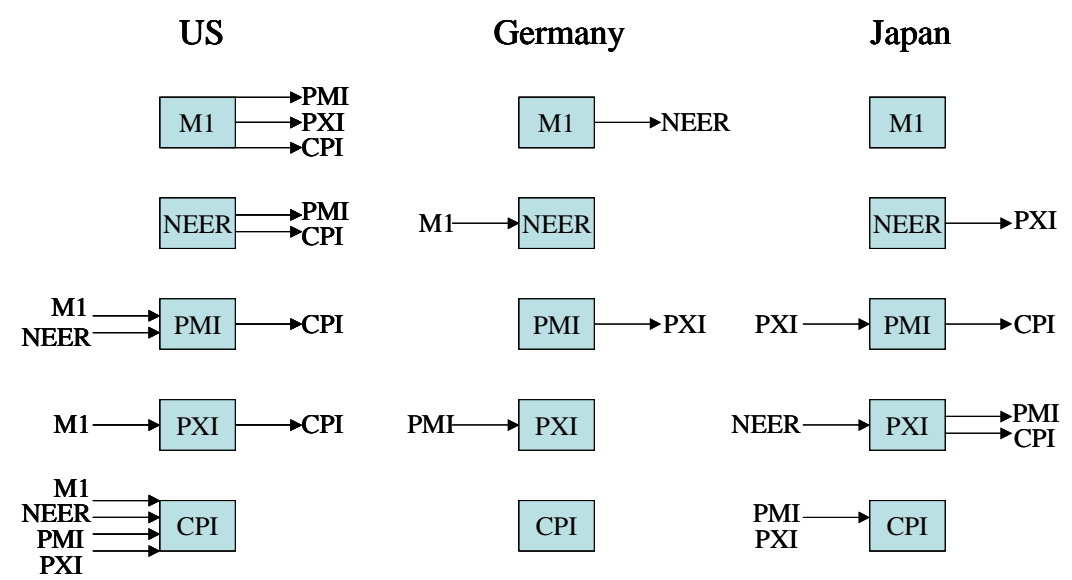

Figure 1: Summary of Pairwise Granger Causality Test Results (with 12 lags and at a 10\% significance level threshold) for the Time Series Used in the VAR Pass-Through Estimates: raw data, largest sample (ending in 1998:12 for German pairs involving M1)

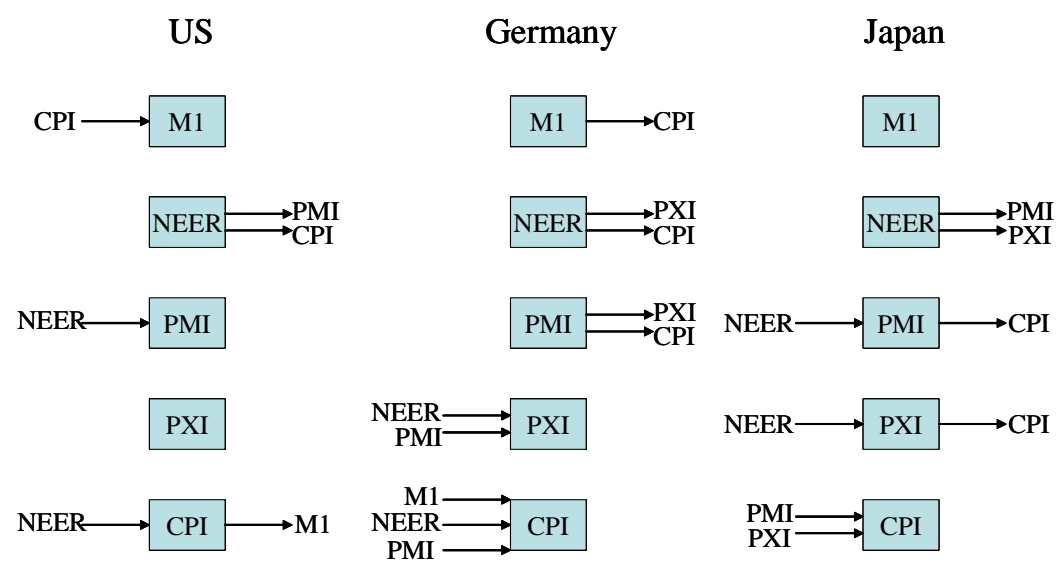

Figure 2: Summary of Pairwise Granger Causality Test Results (with 12 lags and at a 10\% significance level threshold) for the Time Series Used in the VAR Pass-Through Estimates: seasonally adjusted data when seasonality found, largest sample (ending in 1998:12 for German pairs involving M1) 

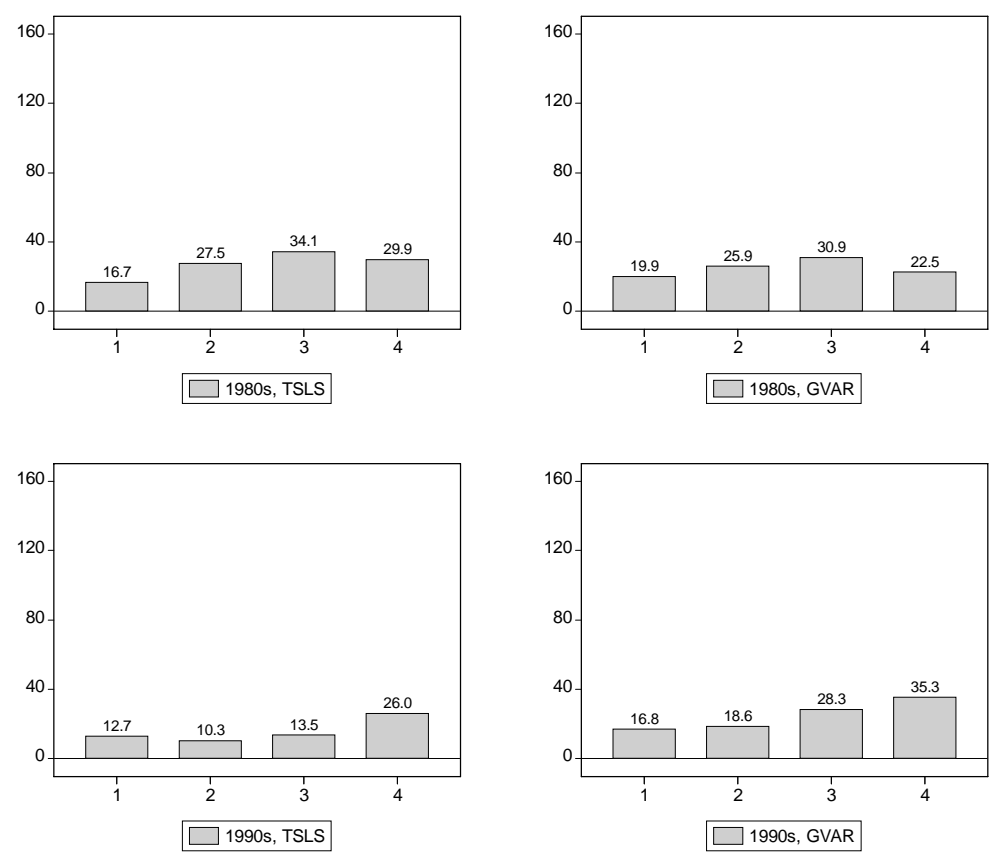

Figure 3: United States - Pass-Through on Import Prices from Monthly Data, in \%, cumulative by quarter
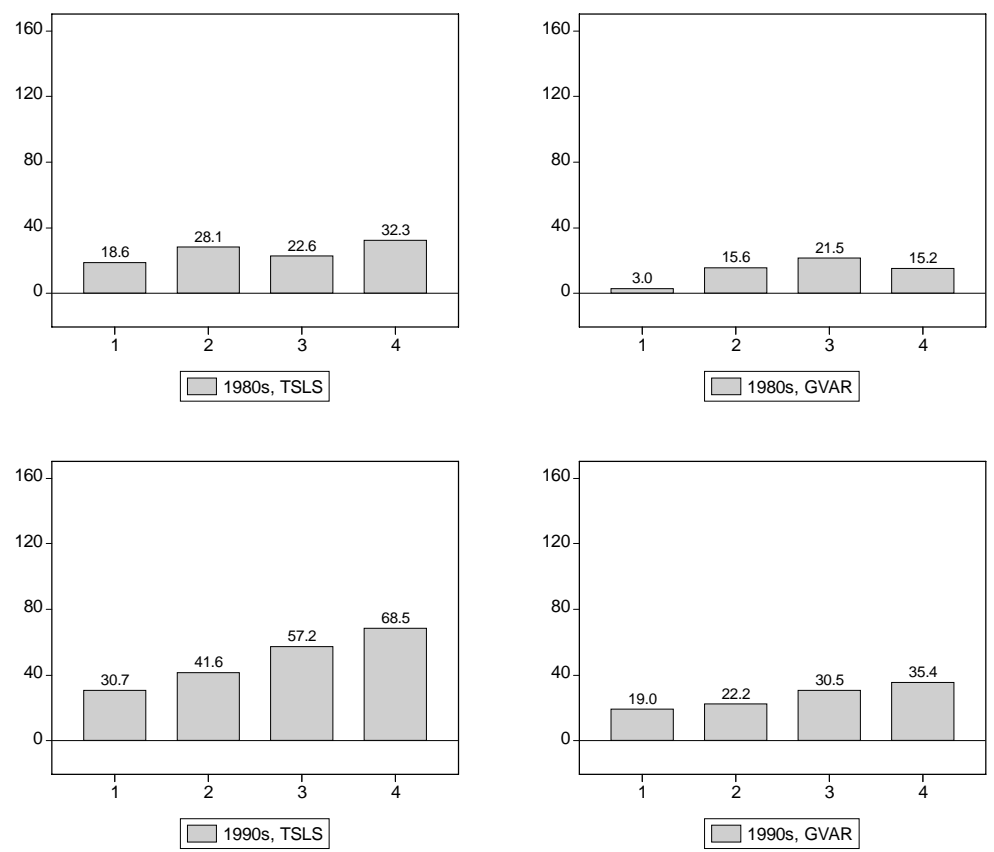

Figure 4: United States - Pass-Through on Import Prices from Quarterly Data, in \%, cumulative by quarter 


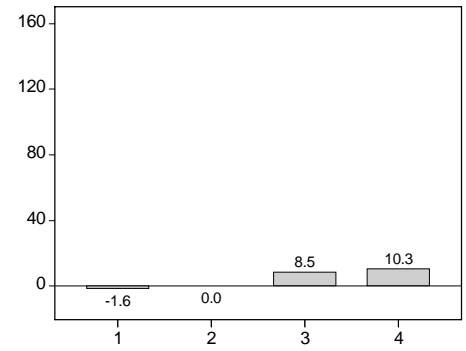

$\square$ 1980s, estimated from monthly data

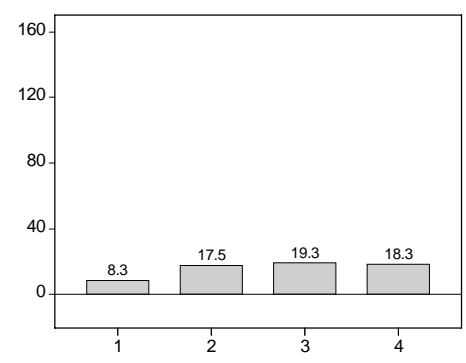

$\square$ 1990s, estimated from monthly data

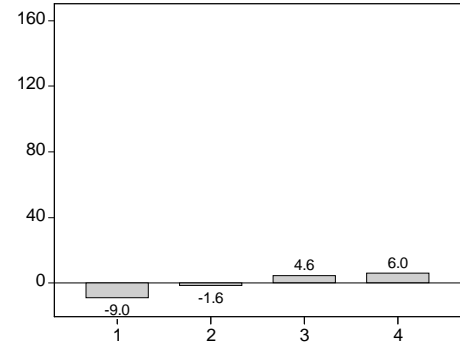

$\square$ 1980s, estimated from quarterly data

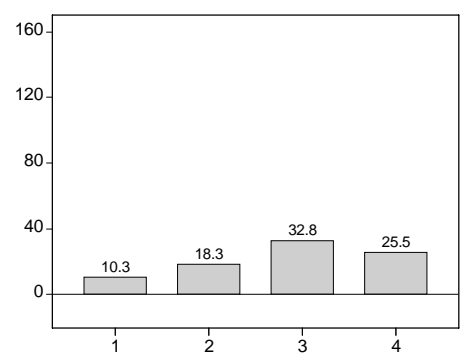

$\square$ 1980s, estimated from quarterly data

Figure 5: United States - Pass-Through on Export Prices, in \%, cumulative by quarter

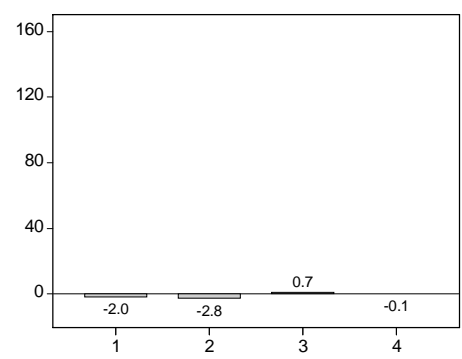

$\square$ 1980s, estimated from monthly data

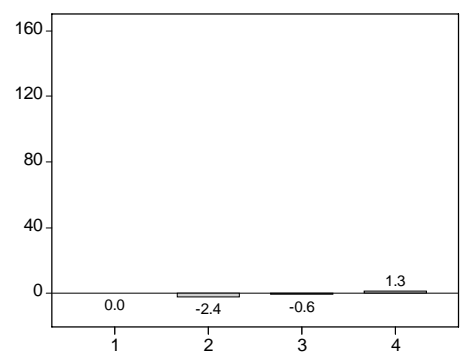

$\square$ 1990s, estimated from monthly data

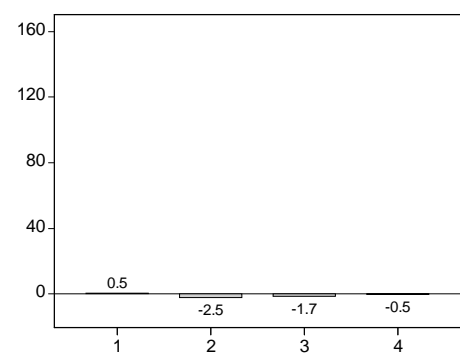

$\square$ 1980s, estimated from quarterly data

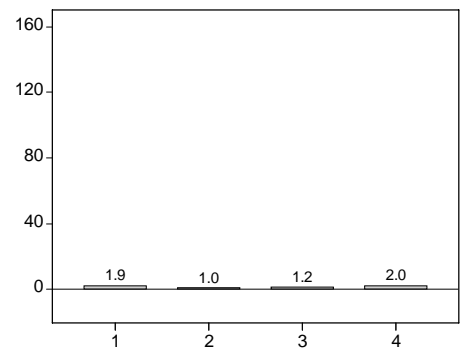

$\square$ 1990s, estimated from quarterly data

Figure 6: United States - Pass-Through on Consumer Prices, in \%, cumulative by quarter 

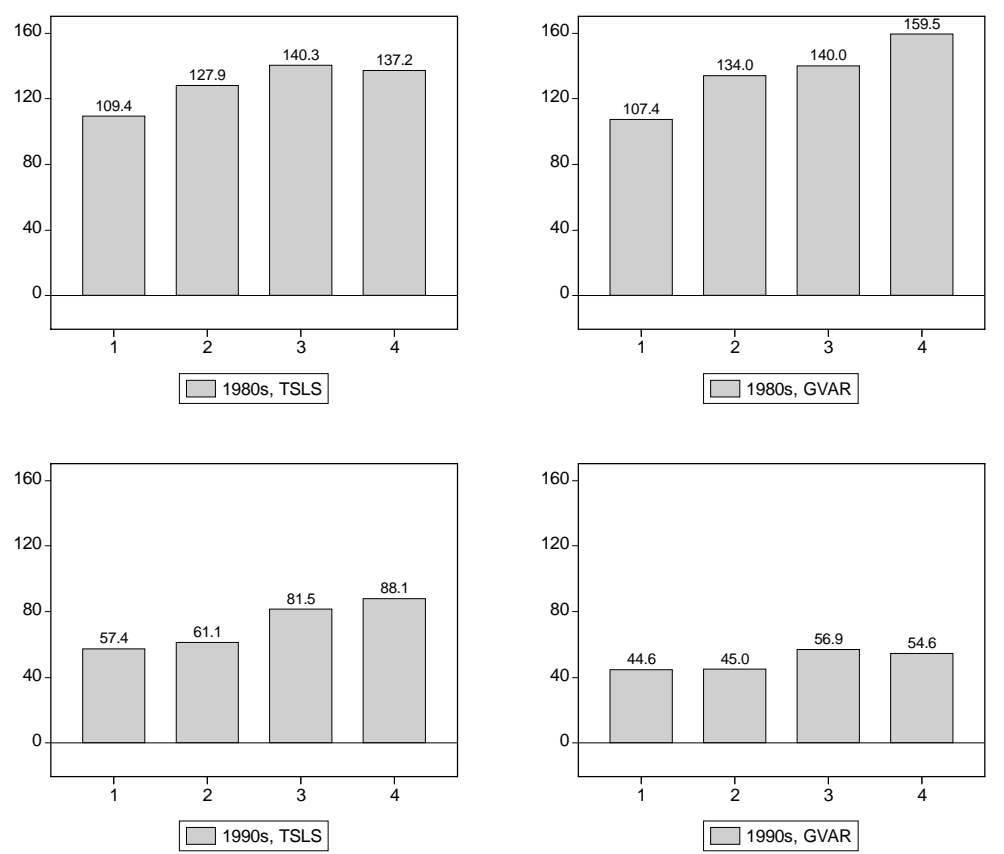

Figure 7: Germany - Pass-Through on Import Prices from Monthly Data, in \%, cumulative by quarter
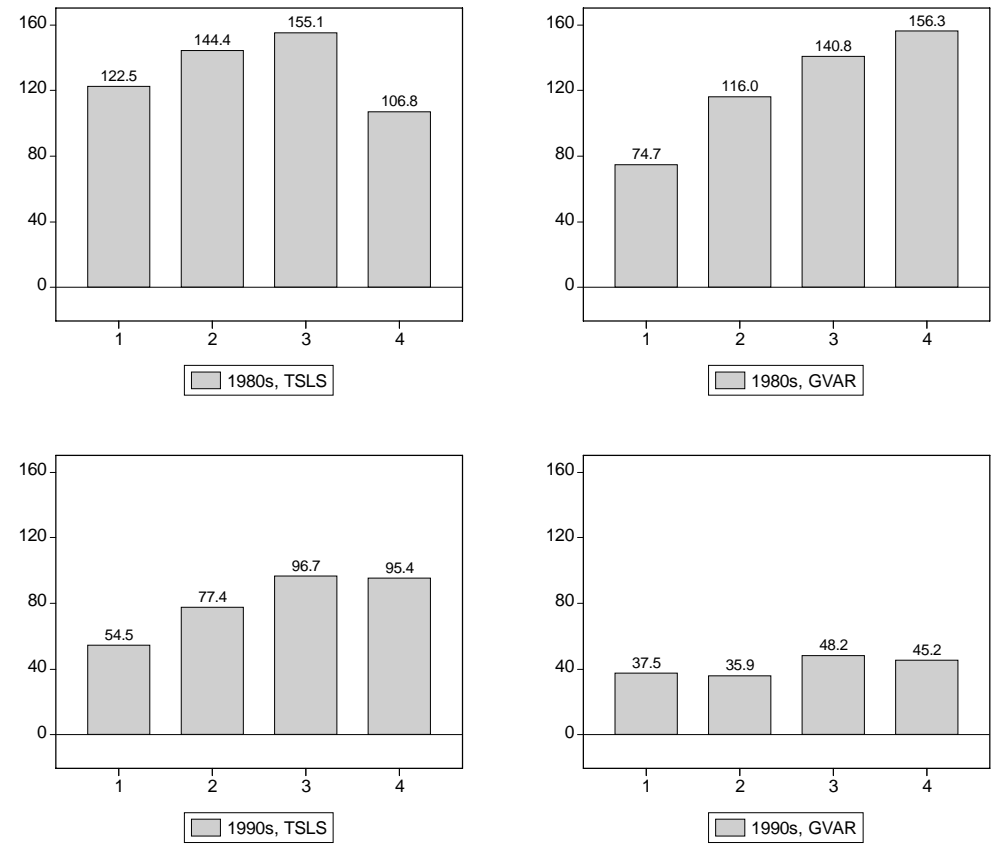

Figure 8: Germany - Pass-Through on Import Prices from Quarterly Data, in \%, cumulative by quarter 


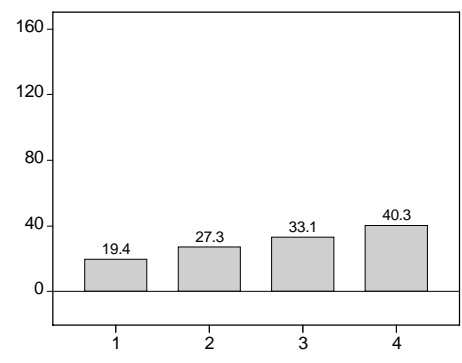

$\square$ 1980s, estimated from monthly data

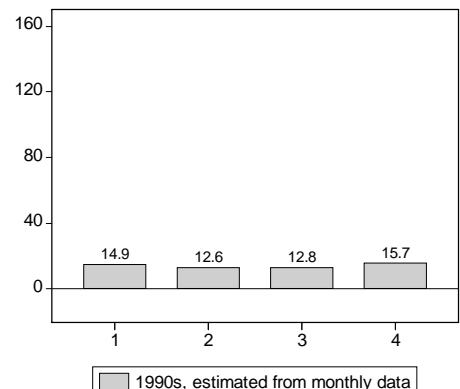

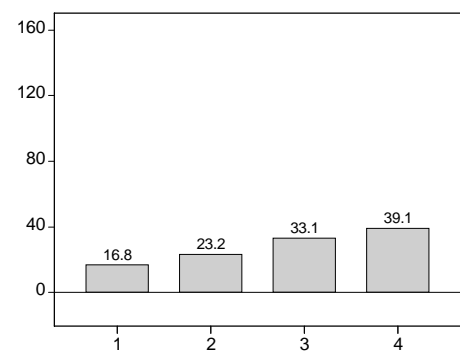

$\square$ 1980s, estimated from quarterly data

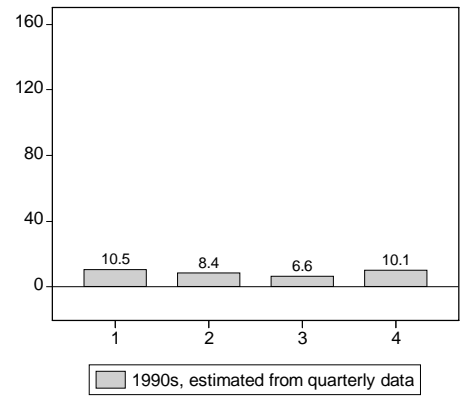

Figure 9: Germany - Pass-Through on Export Prices, in \%, cumulative by quarter
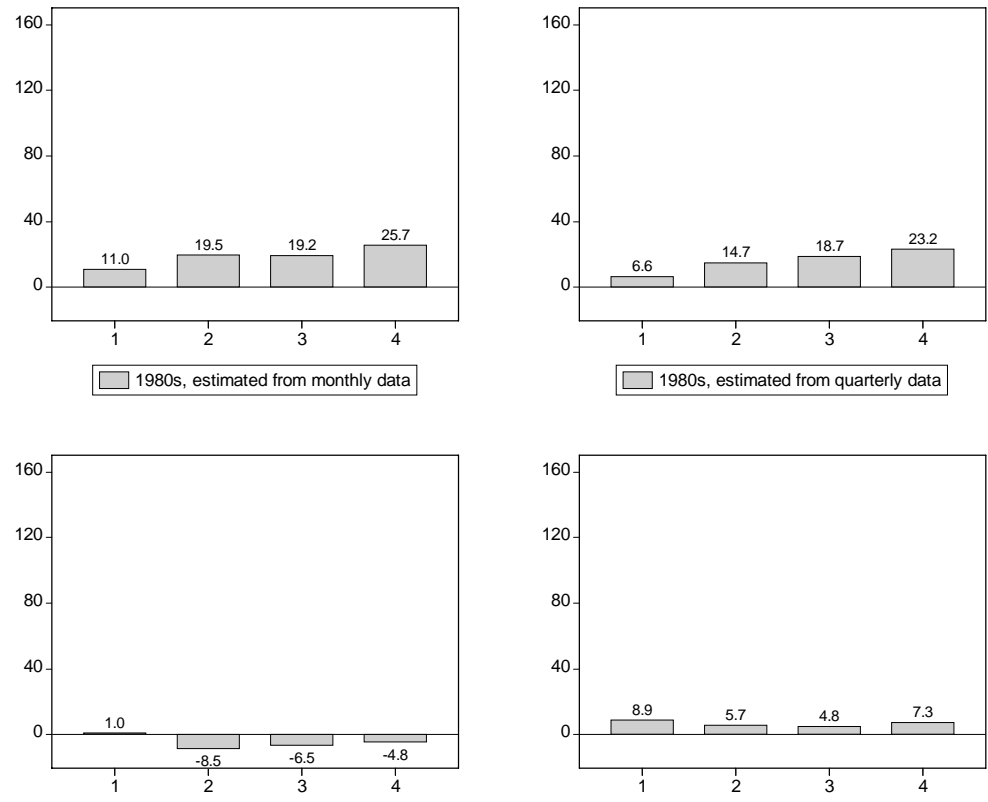

$\square$ 1990s, estimated from monthly data

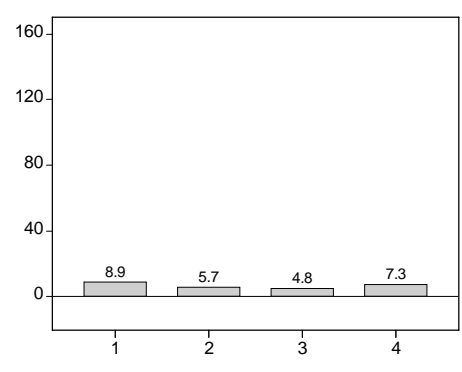

$\square$ 1990s, estimated from quarterly data

Figure 10: Germany - Pass-Through on Consumer Prices, in \%, cumulative by quarter 

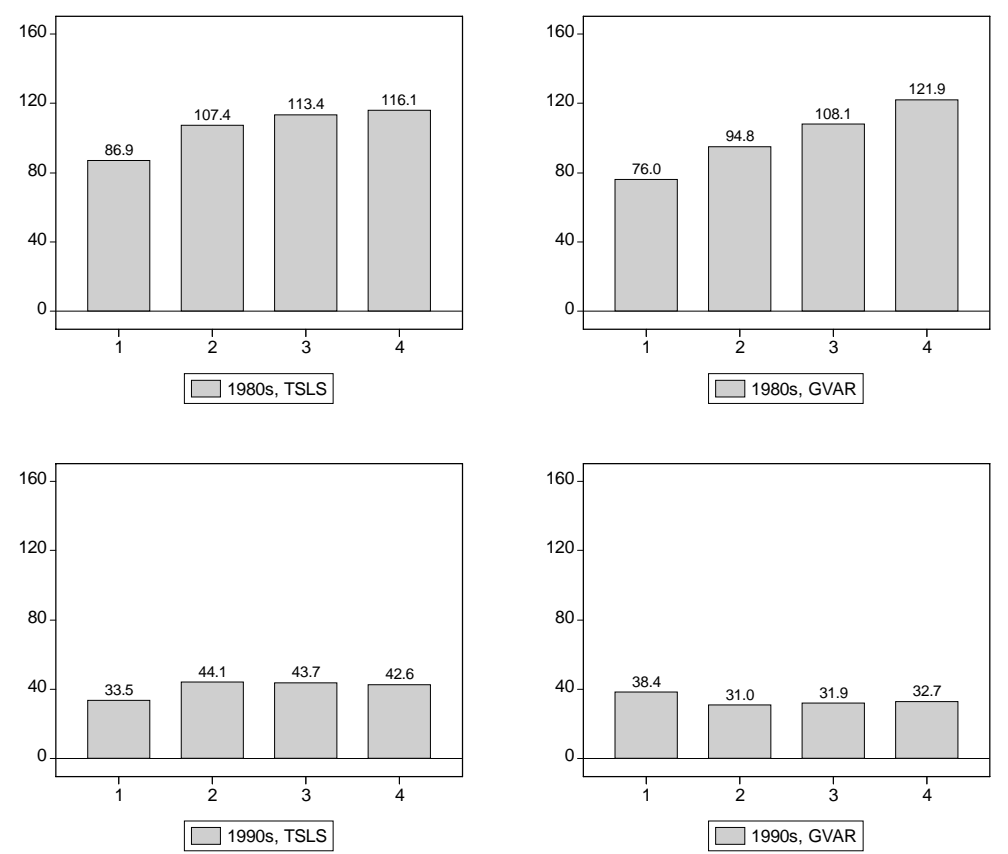

Figure 11: Japan - Pass-Through on Import Prices from Monthly Data, in \%, cumulative by quarter
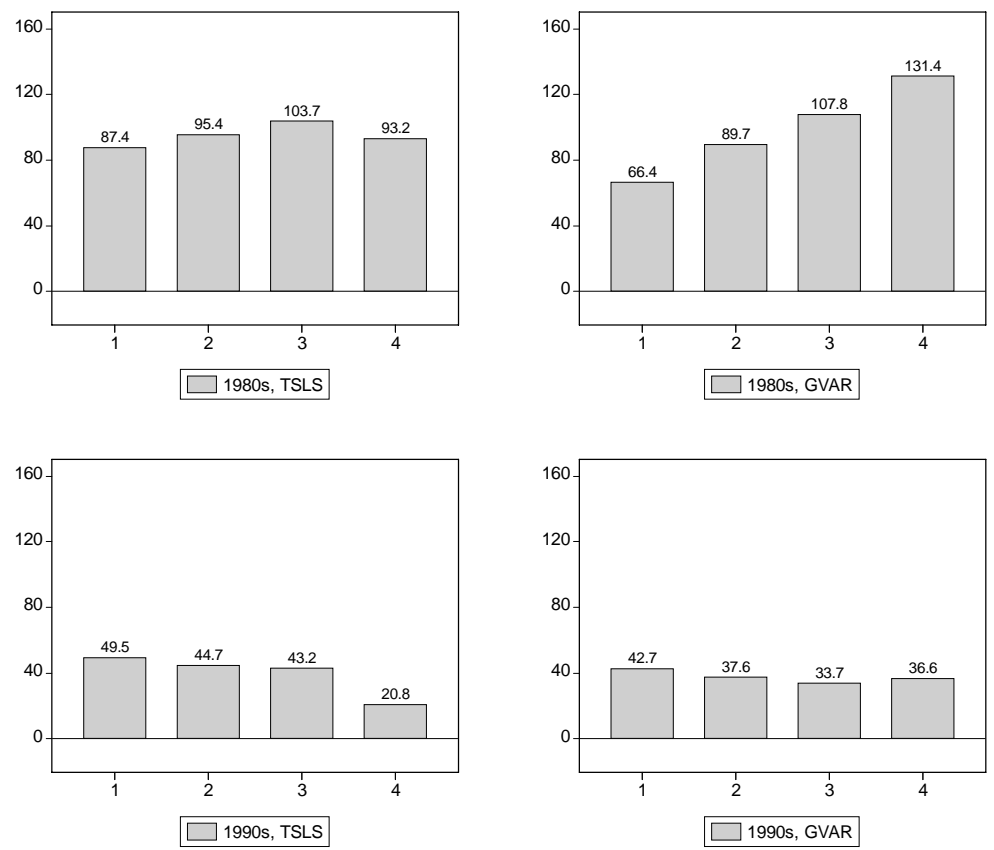

Figure 12: Japan - Pass-Through on Import Prices from Quarterly Data, in \%, cumulative by quarter 

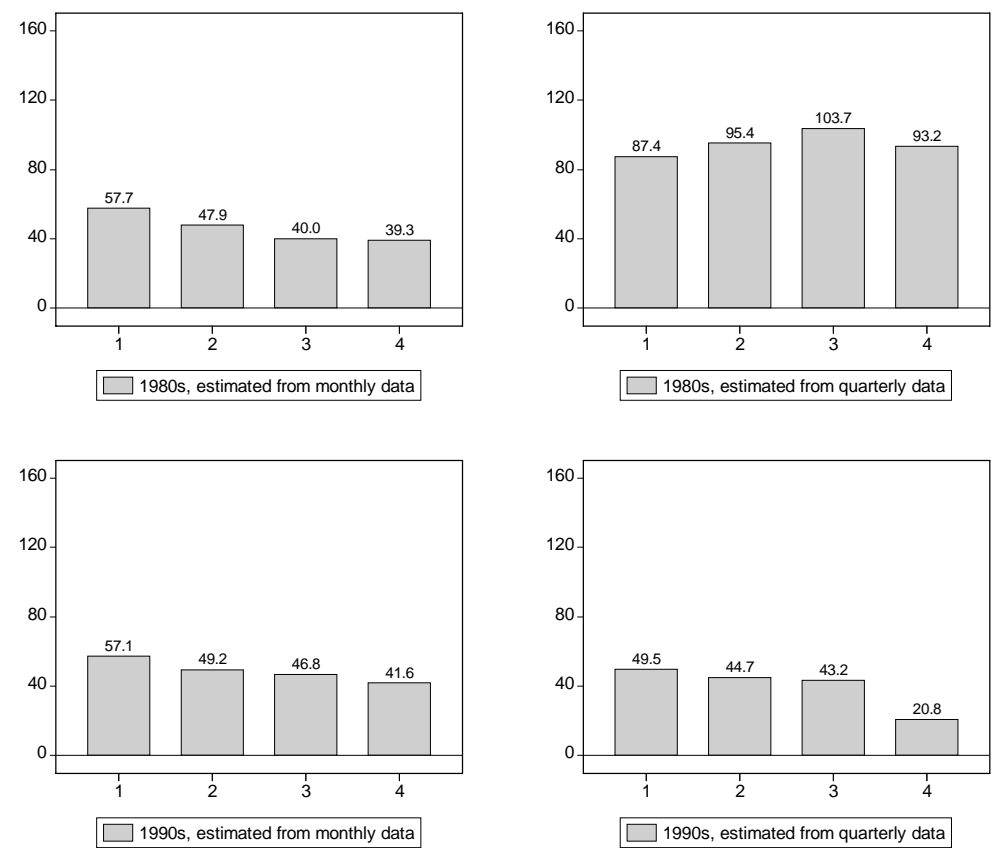

Figure 13: Japan - Pass-Through on Export Prices, in \%, cumulative by quarter
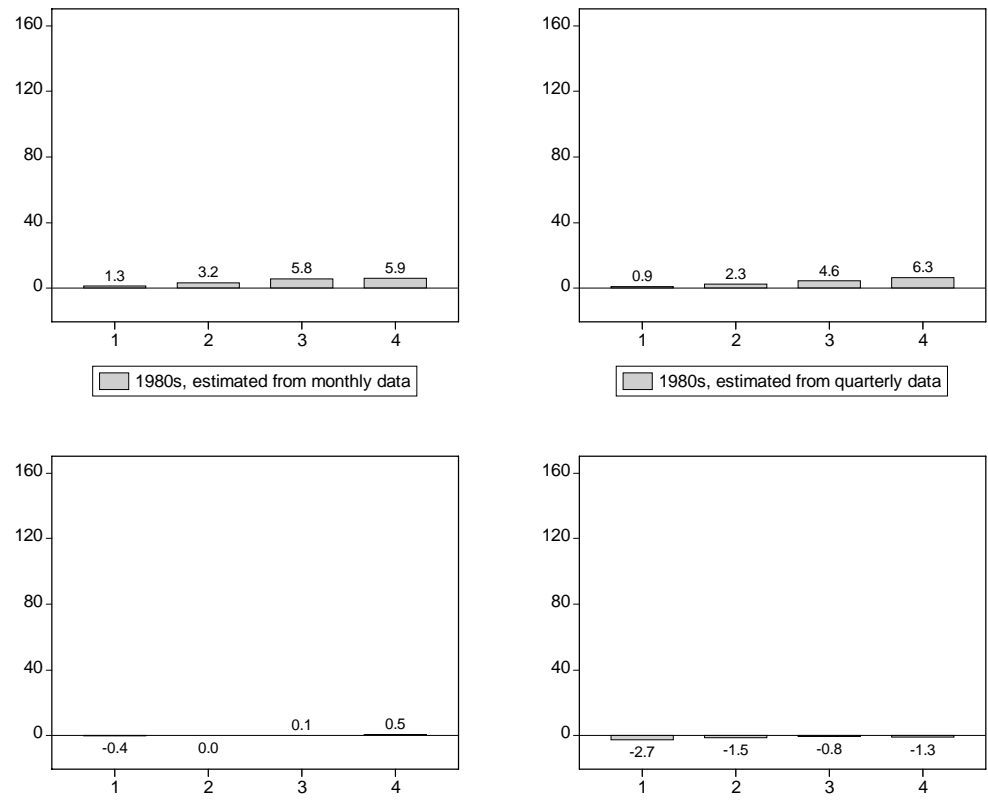

$\square$ 1990s, estimated from monthly data

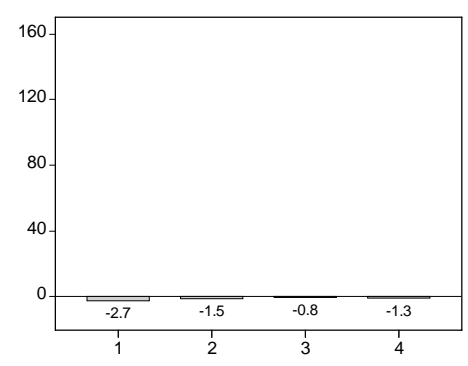

$\square$ 1990s, estimated from quarterly data

Figure 14: Japan - Pass-Through on Consumer Prices, in \%, cumulative by quarter 